\title{
Los orígenes del Solutrense y la ocupación pleniglaciar del interior de la Península Ibérica: implicaciones del nivel 3 de Peña Capón (valle del Sorbe, Guadalajara)
}

\author{
The origins of the Solutrean and the pleniglacial occupation of inner Iberia: implications \\ of the Peña Capón level 3 (Sorbe Valley, Guadalajara, Spain)
}

\author{
Manuel Alcaraz-Castaño (*) \\ Javier Alcolea González (*) \\ Rodrigo de Balbín Behrmann (*)
}

\author{
Miguel Ángel García Valero (**) \\ José Yravedra Sainz de los Terreros (***) \\ Javier Baena Preysler (****)
}

\section{RESUMEN}

Se presentan los resultados del estudio del material arqueológico correspondiente al nivel 3 del abrigo de Peña Capón, cuyo depósito, conocido desde 1970, únicamente había sido objeto de una revisión preliminar a finales de la década de 1990. El análisis de la colección ha incluido el estudio tecnológico y tipológico de la industria lítica y ósea, el análisis zooarqueológico y tafonómico de la fauna, la documentación de grabados sobre soportes óseos, así como la datación radiocarbónica de varias muestras óseas. Los datos obtenidos nos han permitido relacionar el nivel estudiado con las industrias protosolutrenses con puntas de Vale Comprido definidas en la Extremadura portuguesa, lo cual constituye una novedad en la Meseta, donde apenas se conocen datos del Paleolítico Superior anteriores al Solutrense medio. Los resultados son consistentes con la definición del Protosolutrense como una

(*) Área de Prehistoria, Dpto. de Historia I y Filosofía, Universidad de Alcalá. C/ Colegios 2. 28801 Alcalá de Henares. Madrid. Correos e.: manuel.alcaraz@uah.es; javier.alcolea@uah.es; rodrigo.balbin@uah.es

(**) Gestión de Patrimonio, Delegación Educación, Cultura y Deportes. Junta de Comunidades de Castilla-La Mancha. C/ Juan Bautista Topete 1. 19031 Guadalajara.

Correo e: magarciav@jccm.es

(***) Dpto. de Prehistoria, Universidad Complutense de Madrid. Avda. del Profesor Aranguren s/n, 28040, Madrid. Correo e: joyravedra@hotmail.com

(****) Dpto. de Prehistoria y Arqueología, Universidad Autónoma de Madrid. Campus de Cantoblanco. 28049 Madrid. Correo e: javier.baena@uam.es

Recibido 13-II-2012; aceptado 28-V-2012. industria transicional entre el Gravetiense y el Solutrense. Asimismo, la verificación de una ocupación humana en el pie de monte del Sistema Central en las fases más frías del último ciclo glaciar (MIS 2) supone un argumento favorable al definitivo abandono de la hipótesis clásica sobre el despoblamiento del interior de la Península Ibérica durante los momentos más fríos del Paleolítico Superior.

\begin{abstract}
The Peña Capón rockshelter contains an archaeological deposit known since 1970 that was the object of a preliminary study in the late 1990's. In this paper we present a revision of the archaeological material from level 3 that includes the technological and typological study of the lithics and bone tools, the zooarchaeological and taphonomic analysis of the faunal remains, the record of engravings on bones, and the radiocarbon dating of several bone samples. The data obtained has allowed us to relate the level 3 to the Protosolutrean industries with Vale Comprido points defined in the Portuguese Estremadura, a matter that constitutes an important breakthrough within the Meseta area, where little is known about the Upper Palaeolithic prior to the Middle Solutrean. The results are consistent with the definition of the Protosolutrean as a transitional industry between the Gravettian and the Solutrean. Furthermore, the verification of a human settlement in the foothills of the Central System range during the Upper Pleniglacial (MIS 2) strongly points to the abandonment of the classic hypothesis that posit a depopulation of inner Iberia during the coldest stages of the last glacial cycle.
\end{abstract}


Palabras clave: Paleolítico Superior; Protosolutrense; Europa; Meseta; Sistema Central; Cuenca del Tajo; Poblamiento; Cronología.

Key words: Upper Palaeolithic; Protosolutrean; Europe; Iberian Plateau; Iberian Central System; Tagus Basin; Settlement; Chronology.

\section{INTRODUCCIÓN}

\subsection{Localización y marco geográfico del yacimiento de Peña Capón}

El abrigo de Peña Capón se localiza en el valle del río Sorbe, en la provincia de Guadalajara, enmarcado en el sector suroriental del Sistema Central correspondiente a la Sierra de Ayllón y la cuenca alta del Tajo, a unos $3 \mathrm{~km}$ de la localidad de Muriel. Sus coordenadas geográficas son $40^{\circ}$ $57^{\prime} 30$ " N, 30 12' 8" O (Datum ETRS89) y su altitud es de 861 m.s.n.m. El abrigo se sitúa al sur de las sierras alcarreñas del Robledal y del Lobosillo, y al oeste de la Sierra Gorda, en la orla de calizas cretácicas que atraviesa los valles del Jarama y del Sorbe desde Alpedrete de la Sierra hasta Tamajón, abriéndose en un karst formado por los afloramientos carbonatados de los terrenos calcáreos que se extienden hasta el Sistema Ibérico. De orientación NO, se localiza en la margen izquierda del río Sorbe, aprovechando un estrechamiento del valle fluvial (Fig. 1).

\subsection{Historia de la investigación}

La historia del yacimiento arqueológico de Peña Capón comienza en 1970, cuando un equipo dirigido por J. Martínez Santa-Olalla, por entonces director de un ya muy falto de medios Instituto Arqueológico Municipal de Madrid (Quero 2002), emprendió un sondeo arqueológico en el lugar. El conocimiento de la intervención, que nunca fue publicada, proviene exclusivamente de los testimonios orales de algunos miembros del equipo de excavación (Alcolea et al. 1995; Alcolea et al. 1997c). En esta circunstancia actuó como factor principal la muerte del mentor de la intervención dos años después de la misma.
Veinticinco años más tarde, la documentación arqueológica de Peña Capón, hasta entonces completamente inédita, pudo ser rescatada gracias a un proyecto de investigación emprendido por un equipo de la Universidad de Alcalá, en el que figuraban varios de los firmantes de este trabajo (Javier Alcolea González, Rodrigo Balbín Behrmann y Miguel Ángel García Valero). Ayudados por miembros del Grupo de Actividades Espeológicas de Madrid, algunos de los cuales, como A. Alcaína Muñoz, también formaron parte del equipo excavador dirigido por Martínez Santa-Olalla, se lograron recuperar los materiales arqueológicos y la documentación gráfica de la intervención, hasta entonces dispersos en colecciones privadas (Alcolea et al. 1997c: 209).

Una vez se tomó conciencia de la importancia de la colección arqueológica se decidió emprender una excavación sistemática en el yacimiento, que se proyectó para finales del año 1995. Sin embargo, dicha intervención no pudo llevarse a término debido a la inundación del abrigo por la crecida en el embalse de Beleña, que desde su construcción en 1982 venía afectando el entorno inmediato del yacimiento (Alcolea et al. 1997c: 209). Esta desafortunada situación provocó que los materiales e informaciones gráficas y orales que se poseían sobre el depósito arqueológico y su excavación no pudieran ser contrastados con una intervención directa en el sitio, tal como se pretendía. Así, y a pesar de las incertidumbres que provocaba la ordenación de la colección, se propuso una primera asignación, siempre preliminar, para los conjuntos arqueológicos que, según las informaciones del equipo excavador original, podían individualizarse en varios niveles sedimentarios. Se identificaron, de techo a muro, 4 niveles de ocupación, de los que se habían excavado algo más de $6 \mathrm{~m}^{2}$, excepto en el estrato basal donde apenas se había podido intervenir en $1 \mathrm{~m}^{2}$ (Alcolea et al. 1997c: 211-216):

Nivel 1: revuelto superficial que se relacionó con una ocupación solutrense, probablemente superior, otra quizá magdaleniense y otra holocena.

Nivel 2: ocupación solutrense que, por las hojas de laurel y otros elementos foliáceos, se hacía corresponder con su fase media.

Nivel 3: Paleolítico Superior inicial, quizá relacionable con un momento de transición desde el Paleolítico Medio, como atestiguaría la notable aparición de útiles de sustrato y varias puntas cuya morfología se asemejaba a las de Chatelperrón. 


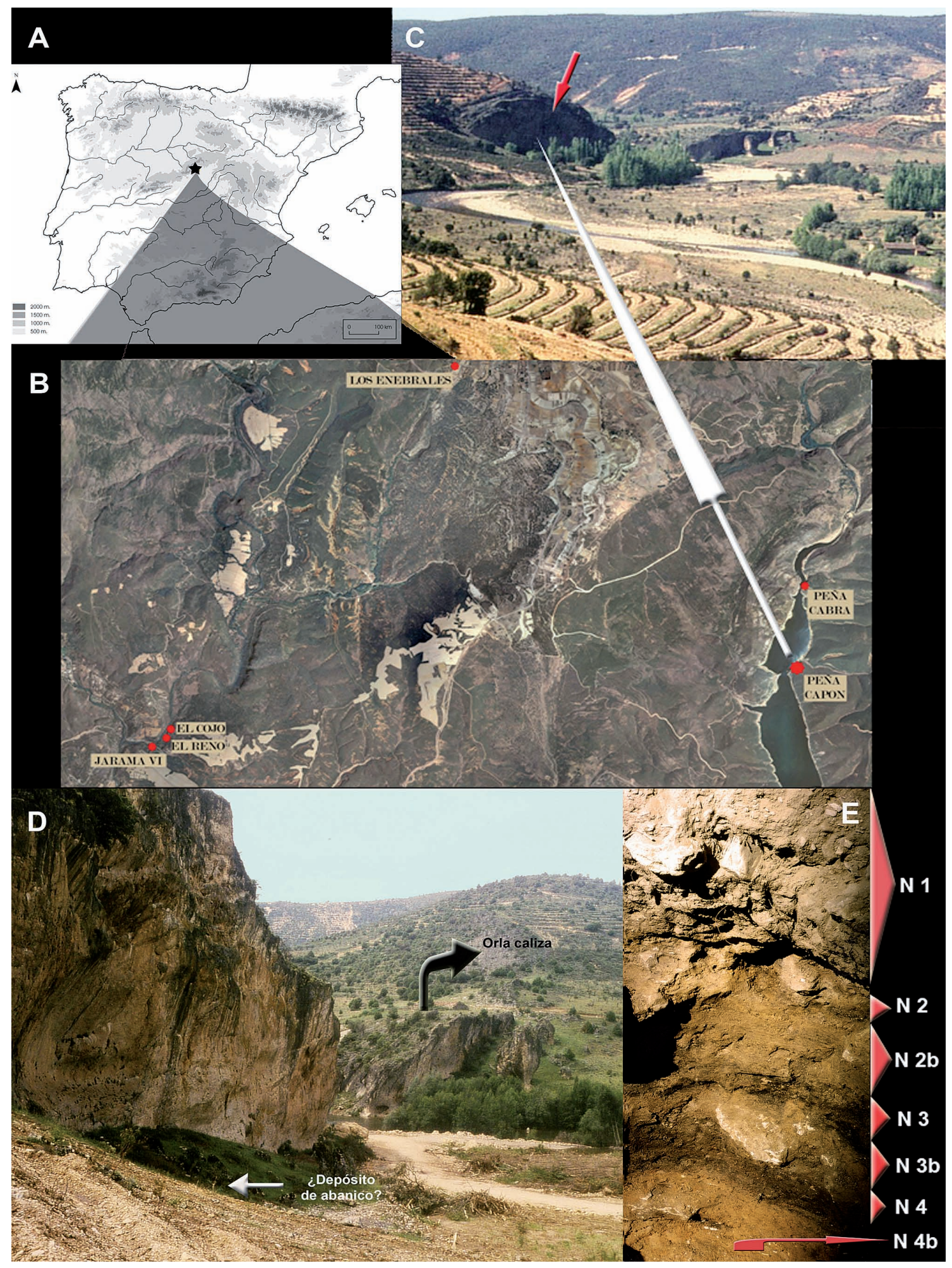

Fig. 1. Localización geográfica del abrigo de Peña Capón en la Península Ibérica (A) y situación de yacimientos del Paleolítico Medio y Superior en los valles del Sorbe y del Alto Jarama (B). Vistas generales del abrigo de Peña Capón en 1980, previas a la construcción del embalse de Beleña (C, D). Estratigrafía documentada en la excavación de 1970 (E).

Trab. Prehist., 70, N. ${ }^{\circ}$, enero-junio 2013, pp 28-53, ISSN: 0082-5638 doi: $10.3989 /$ tp.2013.12101 
Nivel 4: ocupación quizá musteriense, si bien lo exiguo de su material lítico, compuesto por apenas 30 piezas realizadas mayoritariamente en cuarzo y poco diagnósticas, exigía una provisionalidad en su asignación aún mayor que en el resto de niveles.

Esta primera adscripción crono-cultural contó siempre con un viso de provisionalidad, salvo en lo relativo a la innegable existencia al menos de una ocupación solutrense en el sitio. Así lo entendió la comunidad científica, cuyas citas al depósito de Peña Capón hasta hoy siempre han sido lógicamente cautelosas, sobre todo en lo referido a la presencia de una ocupación de los primeros momentos del Paleolítico Superior, cuestión ciertamente excepcional en la Meseta (Baena y Carrión 2006: 47; Delibes y Díez 2006: 16; Mosquera et al. 2007: 151; Peña 2009: 46; Cacho et al. 2010: 117).

La situación del pantano que cubre el abrigo, cuyos estiajes nunca han sido suficientes para permitir una excavación sistemática en el lugar, nos ha impedido en todo este tiempo completar un estudio que en su momento se presentó como preliminar e incompleto (Alcolea et al. 1997c). Nuestro principal objetivo desde 1995 ha sido excavar el depósito aún intacto que conserva el abrigo para así poder contrastar las apreciaciones iniciales. Sin embargo, las expectativas de vislumbrar una pronta excavación del sitio (que parece solo posible de producirse una sequía prolongada, o una limpieza del pantano que por ahora no se encuentra proyectada por las instituciones responsables) son pocas. Por eso nos hemos decidido a completar el estudio con los datos que poseemos, ante la importancia que creemos tiene la secuencia de Peña Capón para el conocimiento de la ocupación superopaleolítica del interior peninsular. Como comprobaremos enseguida, a pesar de la problemática que envuelve la excavación, ordenación y clasificación original de sus materiales, los datos ofrecidos por dicha secuencia pueden aún contribuir notablemente al conocimiento de un período cultural tradicionalmente considerado marginal en nuestra área geográfica, como son las fases iniciales y medias del Paleolítico Superior.

\subsection{El proyecto actual: objetivos y trabajos desarrollados}

Ante la incertidumbre que presenta un depósito sedimentario al que no podemos acceder y cuyo proceso de excavación conocemos de forma parcial, nuestro primer propósito se ha centrado en corroborar con la mayor seguridad posible la integridad tafonómica de los niveles arqueológicos descritos por el equipo de excavación de Santa-Ola1la. Su homogeneidad, al menos en lo referido a los lotes líticos, ya quedó en parte apuntada en la primera revisión de la industria (Alcolea et al. 1997). Resulta relevante una de las fotografías aportadas por el equipo excavador, en la que se documenta la secuencia estratigráfica del sitio y se identifican sin problemas los cuatro niveles fértiles a los que ya hemos aludido, separados por paquetes sedimentarios estériles que habrían impedido una hipotética mezcla de materiales (Fig. 1E). La existencia de un mayor número de unidades sedimentarias o de episodios tafonómicos solo reconocibles mediante la inspección directa del depósito por ahora escapa a nuestro conocimiento. Ello, sin embargo, no tiene por qué poner en cuestión las cuatro grandes unidades sedimentarias, correspondientes a los cuatro niveles arqueológicos descritos. La integridad sedimentológica de esta secuencia se refuerza con lo observado en varias de las fotografías en nuestro poder, y en tomas aéreas anteriores a la construcción de la Presa de Beleña. En ellas aparecen indicios de que la dinámica sedimentaria del abrigo incluyó un relleno final de abanico aluvial, quizá postglaciar, que habría sido en parte responsable de la conservación del depósito (Fig. 1C, D).

Por otro lado, nuestro objetivo fundamental ha sido la propia caracterización de las ocupaciones documentadas por las colecciones industriales y faunísticas presentes en la secuencia de Peña $\mathrm{Ca}$ pón. Su importancia creemos reside en que suponen uno de los escasos testimonios de las fases medias del Paleolítico Superior en la Meseta y, en el caso del nivel 3, de momentos incluso anteriores dentro de la secuencia superopaleolítica, hasta ahora inéditos. Para ello, hemos llevado a cabo un análisis tecnológico y tipológico de la industria lítica y ósea, un estudio zooarqueológico y tafonómico de la fauna, así como un programa preliminar de dataciones AMS.

\section{RESULTADOS}

\subsection{Dataciones C14 AMS}

Ante la imposibilidad de datar muestras recogidas en la actualidad con los protocolos ade-

Trab. Prehist., 70, N. ${ }^{\circ}$ 1, enero-junio 2013, pp 28-53, ISSN: 0082-5638 doi: $10.3989 /$ tp.2013.12101 
cuados, hemos recurrido a los restos faunísticos de la colección original, a pesar de los problemas de contaminación que pueden arrastrar. Hemos fechado muestras de todos los niveles excepto del 1 , ya que al albergar materiales correspondientes a distintas ocupaciones, resulta imposible asignar sus restos óseos a cada una de ellas.

Las dataciones obtenidas (Tab. 1), todas a partir de piezas dentarias, son coherentes con la secuencia estratigráfica y no presentan inversiones cronológicas. Sin embargo, la escasa diferencia entre las fechas de los niveles 2 y 3 nos obliga a tomar estos resultados con precaución y valorar la posibilidad de que haya variaciones con respecto a la edad real de las muestras En todo caso, la existencia de paquetes sedimentarios estériles entre los niveles arqueológicos (vide supra), así como el distinto estado de conservación que muestran las superficies de los restos faunísticos de los distintos niveles, nos conduce a poner en duda la posibilidad de una mezcla de materiales, ya fuera resultado de procesos postdeposicionales o del trasiego del material desde su excavación hasta la actualidad. El escaso número de muestras analizadas, sobre las que por ahora no hemos podido aplicar los más recientes protocolos de tratamiento previo del hueso, nos impiden contar con las mismas garantías sobre un hipotético rejuvenecimiento de alguna muestra como resultado de la contaminación. Esperamos poder desarrollar en el futuro un segundo programa de datación que incluya ese pretratamiento mediante ultrafiltración (Higham 2011). Asimismo, también esperamos poder datar mediante termoluminiscencia algunos elementos de industria lítica que muestran evidencias de haber sido sometidos a fuentes de calor, completando un corpus de datos cronométricos que en la actualidad, aunque operativo, resulta escaso y debe entenderse solo como una primera aproximación (Tab. 1).
En lo que se refiere al ajuste de las dataciones obtenidas con la asignación crono-cultural propuesta en Alcolea et al. (1997), lo primero que debe considerarse, más allá de las precauciones señaladas más arriba, es que no contamos con una secuencia cronológica de referencia para el Paleolítico Superior de la Meseta, donde apenas existen fechas publicadas anteriores al Tardiglaciar (Delibes y Díez 2006; Cacho et al. 2010). Nos vemos obligados a comparar las cronologías obtenidas con las secuencias propuestas en otras regiones de la Península Ibérica, si bien creemos que la acomodación de la secuencia meseteña a esas cronologías resultaría un ejercicio excesivamente apriorístico y forzado. Parece innegable que la única datación que a priori es coherente con su atribución industrial es la obtenida en el nivel 2, pues una fecha en torno a $20 \mathrm{ka}$ C14 BP es aceptable para un conjunto solutrense, si bien ciertamente antigua para una industria del Solutrense medio. Por el contrario, la datación del nivel 4 se presenta como excesivamente reciente para un contexto del Paleolítico Medio. Ello abunda en la incertidumbre que ya de por sí planteaba lo exiguo y poco informativo de la muestra lítica de este nivel, cuyo carácter musteriense ha de ser, tras esta datación, definitivamente cuestionado. La fecha obtenida para el nivel 3 , inicialmente atribuido a un genérico Paleolítico Superior inicial, resulta igualmente problemática, pues se sitúa, al igual que la referida al nivel 2, en un rango plenamente solutrense. En las líneas siguientes incidiremos en la caracterización cronocultural de este último nivel.

\subsection{La industria lítica del nivel 3}

Las especiales características de la colección industrial estudiada, cuyo proceso de excavación

\begin{tabular}{ccccccc}
\hline Nivel & Muestra & Ref. laboratorio & $\begin{array}{c}\text { 13C/12C } \\
\text { Ratio }\end{array}$ & C14 BP & Cal BP (95,4\%) & Media Cal BP \\
\hline $\mathbf{2}$ & Diente & Beta -246880 & -20.2 & $19930 \pm 110$ & $24227-23420$ & 23800 \\
\hline $\mathbf{3}$ & Diente & Beta -246879 & -20.4 & $19980 \pm 110$ & $24279-23468$ & 23866 \\
\hline $\mathbf{4}$ & Diente & Beta -246878 & -20.5 & $21220 \pm 120$ & $25817-24971$ & 25349 \\
\hline
\end{tabular}

Tab. 1. Dataciones AMS de Peña Capón (valle del Sorbe, Guadalajara). La calibración, basada en la curva IntCal09 (Reimer et al. 2009), se ha calculado mediante el programa OxCal 4.1. (Bronk Ramsey 2009).

Trab. Prehist., 70, N. ${ }^{\circ}$ 1, enero-junio 2013, pp 28-53, ISSN: 0082-5638 doi: $10.3989 /$ tp.2013.12101 
e inmediata conservación conocemos de forma parcial, nos han hecho valorar una serie de cuestiones previas a su análisis pormenorizado. Los datos estadísticos extraídos no deben entenderse como absolutos, sino valorarse en términos de tendencia, ya que es probable que la colección esté seleccionada, como indica el escaso número de desechos de talla y el gran porcentaje de material retocado, sobre todo en el caso de la producción en sílex (Tab. 2). En este sentido, si bien creemos que los datos cuantitativos obtenidos aportan información relevante para la caracterización del lote industrial, los datos cualitativos han sido más determinantes, permitiéndonos en definitiva plantear una asignación crono-cultural para la colección arqueológica del nivel. Esta circunstancia, unida a lo escaso de la muestra estudiada, nos ha disuadido de realizar análisis tipométricos e índices tipológicos, si bien presentamos los números totales y porcentajes de las principales categorías tecnológicas y atributos técnicos, así como de los morfotipos identificados. En todo caso, como comentaremos enseguida, aunque minoritarios, hay elementos líticos de pequeño tamaño y desechos de talla, unidos a un número considerable de productos corticales y de acondicionamiento (Tab. 2). Ello nos permite afirmar que la selección del material no debió ser tan exhaustiva como para limitarse a los soportes retocados y otros elementos susceptibles de ser identificados positivamente por los excavadores.

\begin{tabular}{|c|c|c|c|c|c|}
\hline & Sílex & $\begin{array}{c}\text { Cuarzo/ } \\
\text { Cristal } \\
\text { de roca }\end{array}$ & Cuarcita & TOTAL & $\%$ \\
\hline Núcleos & 13 & 4 & 0 & 17 & 4,81 \\
\hline $\begin{array}{c}\text { Descortezado } \\
\text { y preparación }\end{array}$ & 17 & 4 & 0 & 21 & 5,94 \\
\hline $\begin{array}{c}\text { Acondicio- } \\
\text { namientos }\end{array}$ & 33 & 3 & 0 & 36 & 10,19 \\
\hline $\begin{array}{c}\text { Desechos } \\
\text { de talla } \\
\text { (chunk y débris) }\end{array}$ & 9 & 6 & 0 & 15 & 4,24 \\
\hline Soportes brutos & 101 & 36 & 2 & 139 & 39,37 \\
\hline $\begin{array}{c}\text { Soportes } \\
\text { retocados }\end{array}$ & 107 & 17 & 1 & 125 & 35,41 \\
\hline T0TAL & 280 & 70 & 3 & 353 & 100 \\
\hline \% & 79,32 & 19,83 & 0.84 & 100 & \\
\hline
\end{tabular}

Tab. 2. Número de efectivos industriales y porcentajes según categorías tecnológicas y materias primas del nivel 3 de Peña Capón (valle del Sorbe, Guadalajara).
El lote industrial del nivel 3 de Peña Capón, proveniente de una extensión de algo más de $6 \mathrm{~m}^{2}$, se compone de 353 efectivos (199 enteros y 154 fracturados). La mayoría se presentan sobre sílex, seguidos de los realizados en cuarzo (habitualmente en su variedad hialina o cristal de roca), que alcanzan prácticamente el $20 \%$ de la colección. Les acompaña una muestra insignificante de piezas en cuarcita (Tab. 2). Hemos distinguido al menos ocho variedades de sílex atendiendo a su coloración. A la espera de un estudio petrológico exhaustivo previsto para un futuro cercano, no podemos precisar ni sus características litológicas ni sus posibles lugares de captación. El simple análisis de visu apunta a la más que probable presencia de varios tipos de sílex del sector Norte de los páramos del Tajo (Parcerisas y Tarriño 2008), lo que indicaría una procedencia cercana de gran parte de la materia prima explotada (Tab. 2).

El estado de conservación de la industria es óptimo, pues las alteraciones de las superficies se reducen a algunos elementos patinados $(11,6 \%)$ y alterados térmicamente $(4,24 \%)$, siendo muy marginales la deshidratación, el rodamiento y el pseudorretoque. Estos datos apuntan a un escaso movimiento mecánico del conjunto industrial, no constatándose episodios de transporte natural o alteraciones postdeposicionales que hayan modificado significativamente las superficies de las piezas. Por tanto, tampoco existen indicios en este ámbito para dudar de la integridad estratigráfica del depósito, o al menos que nos induzcan a proponer alteraciones tafonómicas significativas.

Si discriminamos los efectivos industriales según un esquema cronológico básico de la cadena operativa, los primeros momentos del proceso de captación y talla están escasamente representados en el yacimiento, mientras las fases de plena producción, consumo y abandono han conservado mayores elementos (Fig. 2A). Esta tendencia, que además se comprueba en el alto número de soportes brutos y retocados recuperados (Tab. 2), debe valorarse, una vez más, con las pertinentes precauciones debido a las incertidumbres que plantean la excavación y conservación de la colección. Esto resulta especialmente relevante para el material retocado, cuya cantidad $(35,4 \%$ de la muestra total) se antoja ciertamente elevada en comparación con los soportes de plena producción no retocados $(39,4 \%)$. En todo caso, creemos que los datos nos informan de una tendencia que, a pesar de 
las incertidumbres comentadas, debe relacionarse con una actividad de talla en el sitio centrada en la explotación de núcleos ya preparados, que se introdujeron en el yacimiento mayoritariamente desprovistos de córtex, y sobre todo con el consumo, reutilización y abandono de material retocado.

\subsubsection{Primeras fases de la cadena operativa. 1: inicio de la talla y 2: plena producción}

Los productos relacionados con la fase $1 \mathrm{del}$ proceso de talla, en la que incluimos los productos de descortezado y preparación de los núcleos, apenas alcanzan un 6\% del total (Tab. 2). En consonancia, la corticalidad del conjunto es escasa (Fig. 2B): la mayoría de las piezas, tanto en sílex $(67,1 \%)$ como en cuarzo/cristal de roca $(81,4 \%)$, carecen de córtex (categoría 0). En las que existe presencia cortical se restringe a un escaso porcentaje de la superficie de la pieza (categorías IV-VI), pudiendo por tanto encuadrarse en fases más avanzadas de la producción.

Pueden conectarse con esta fase, por su alto índice de corticalidad (categorías I-III), fundamentalmente lascas, aunque también algunas láminas. Unas y otras están relacionadas con las extracciones de inicio de la explotación, que habrían abierto los nódulos sin ninguna preparación específica. Completan los elementos encuadrables en la fase 1 algunas lascas de preparación de planos de percusión, además de una lámina de cresta.

En la fase 2 de plena producción, la más representada en la colección, hemos incluido soportes brutos, productos de acondicionamiento y desechos de talla (Tab. 2). Destacan especialmente los soportes brutos y los acondicionamientos laminares correspondientes a la explotación del sílex. Entre los primeros predominan las láminas y lascas en número casi idéntico, si bien existe un porcentaje no desdeñable de laminitas y, en menor medida, lascas laminares (Tab. 3). Sin embargo, si nos fijamos en las materias primas, en el sílex los soportes laminares $(41,6 \%)$ cobran mayor relevancia que las lascas $(29,7 \%)$, sin variar el número de laminitas $(19,8 \%)$ y lascas laminares $(8,9 \%)$. Por el contrario, en la producción de cuarzo las lascas son más del doble $(47,2 \%)$ que las láminas $(22,2 \%)$, manteniéndose laminitas $(19,4 \%)$ y lascas laminares $(11,1 \%)$ en porcentajes muy similares a los del sílex. Nuestro desconocimiento del

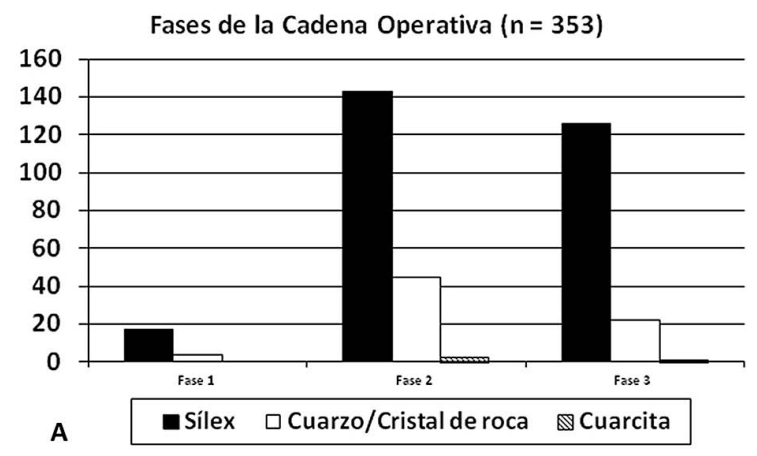

Categorías corticales (\%)

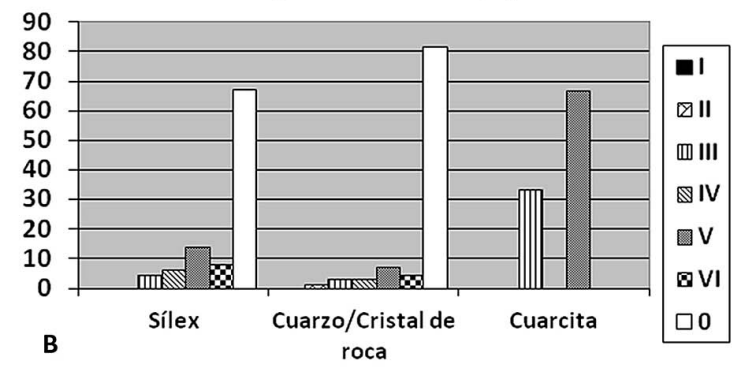

Fig. 2. Peña Capón (valle del Sorbe, Guadalajara), nivel 3. A. Fases de la cadena operativa según materias primas. Fase 1. Inicio de la talla: productos de descortezado y preparación; Fase 2. Plena producción: soportes brutos y productos de acondicionamiento; Fase 3. Consumo y abandono: soportes retocados y núcleos agotados. B. Porcentaje de categorías corticales según la cantidad de córtex en anverso y talón: I. 100\% en anverso y talón (entame); II. 100\% en anverso; III. 100-66\%; IV. 66-33\%; V. 33-10\%; VI. <10\%; 0 . Sin córtex.

proceso de excavación del yacimiento nos obliga a poner en cuarentena el porcentaje de laminitas, que puede que fuera aún mayor.

\begin{tabular}{|c|c|c|c|c|c|}
\hline & Sílex & $\begin{array}{c}\text { Cuarzo/ } \\
\text { Cristal } \\
\text { de roca }\end{array}$ & Cuarcita & TOTAL & $\%$ \\
\hline Láminas & 42 & 8 & 0 & 50 & 35,97 \\
\hline Laminitas & 20 & 7 & 0 & 27 & 19,42 \\
\hline Lascas & 30 & 17 & 2 & 49 & 32,25 \\
\hline $\begin{array}{c}\text { Lascas } \\
\text { laminares }\end{array}$ & 9 & 4 & 0 & 13 & 9,35 \\
\hline TOTAL & 101 & 36 & 2 & 139 & 100 \\
\hline
\end{tabular}

Tab. 3. Número de soportes brutos según materias primas y porcentajes totales del conjunto industrial del nivel 3 de Peña Capón (valle del Sorbe, Guadalajara). 

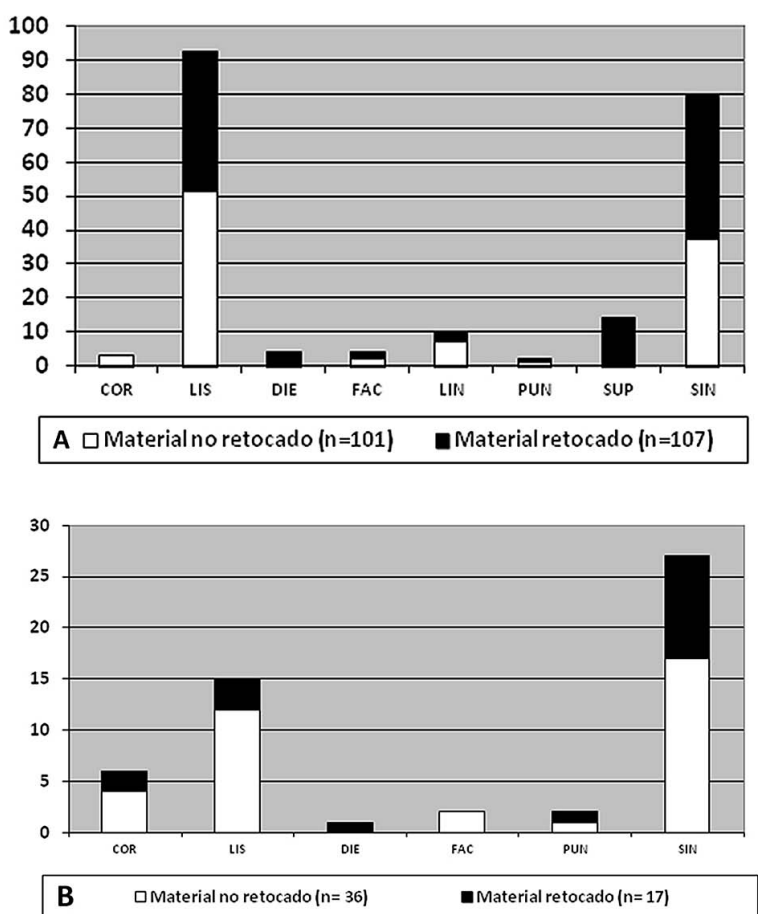

Fig. 3. Peña Capón (valle del Sorbe, Guadalajara), nivel 3. Relación entre tipos de talones de soportes brutos y retocados: A. en sílex; B. en cuarzo/cristal de roca. De izquierda a derecha: A: Cortical, Liso, Diedro, Facetado, Lineal, Puntiforme, Suprimido y Sin talón. B: Cortical, Liso, Diedro, Facetado, Puntiforme, Sin talón.

Considerando solo los soportes que conservan su sector proximal, el conjunto está fuertemente dominado por los talones lisos. Sobre sílex, estos son mayoritarios entre los soportes brutos $(79,65 \%)$ y los retocados $(63,1 \%)$ (Fig. 3A). En la explotación del cuarzo, los talones lisos son igualmente dominantes, alcanzando el 63,1\% y el $42,8 \%$ de brutos y retocados respectivamente (Fig. 3B). Mención especial merecen los talones suprimidos. Suponen el 21,5\% del material retocado en sílex y comentaremos más adelante su significación. La mayoría de soportes brutos y acondicionamientos en los que se ha podido identificar con una seguridad aceptable la técnica de talla presentan los atributos típicos de la percusión directa mediante rocas duras (Pelegrin 1995: 6768). Sin embargo, se han advertido varias láminas con bulbos difusos, escamas bulbares de recorrido longitudinal a partir del punto de impacto, e incluso algunos talones labiados. Estos estigmas en su conjunto proponen el uso de técnicas de percusión llevadas a cabo con materiales pétreos de mayor elasticidad (i.e. "piedra blanda"), quizá areniscas, tal como ha sido reconocido en varios contextos del Paleolítico Superior europeo (Pelegrin 1995: 104, 2000: 80) y la Middle Stone Age africana (Soriano et al. 2007: 691). Como comentaremos posteriormente, esta última técnica ha sido identificada fundamentalmente en los soportes retocados o clasificados como morfotipos. La percusión elástica a partir de percutores orgánicos no ha podido ser reconocida, si bien algunos soportes, de los que desgraciadamente no se ha conservado el sector proximal, poseen espesores reducidos que, aunque no de forma inequívoca, podrían indicar su presencia testimonial (Fig. 5: 1 y Fig. 6: 5).

También se ha constatado una cierta preparación de los planos de percusión a partir de los estigmas de abrasión y raspado observados en algunos talones y sectores proximales de los anversos. Estas preparaciones afectan al 18,8\% de los soportes brutos y al $21,2 \%$ de los acondicionamientos en sílex, mientras se reducen al 3\% de los soportes brutos en la producción del cuarzo.

Los productos de acondicionamiento destinados a la reactivación morfoestructural de los

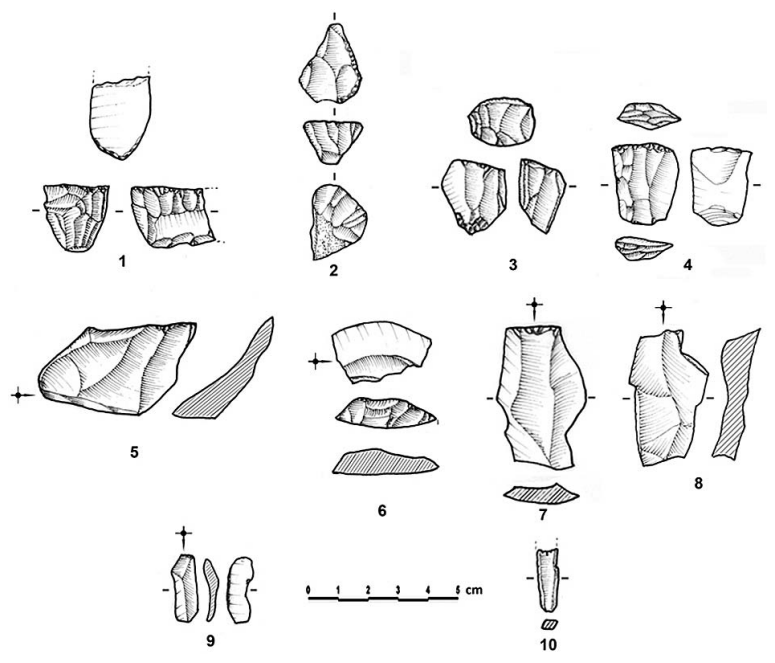

Fig. 4. Industria lítica del nivel 3 de Peña Capón (valle del Sorbe, Guadalajara). 1 y 2: núcleos de laminitas tipo raspador carenado; 3: núcleo de laminitas piramidal unipolar (Fig. 6.2.); 4: núcleo bipolar-pieza astillada (Fig. 6.1.); 5: flanco de núcleo transversal; 6: tableta; 7 y 8: flancos de núcleo longitudinales; 9: laminita Dufour (Fig. 6.4.); 10: laminita-astilla. Todos en sílex excepto 2 en cuarzo y 9 en cristal de roca. Dibujos Javier Alcolea. 
núcleos suponen un 10,2\% del total de la muestra (Tab. 2). La gran mayoría corresponden a la gestión laminar del sílex $(11,8 \%$ de la producción en esta materia prima), habiéndose documentado tabletas (Fig. 4: 6) y semitabletas, así como flancos de núcleo longitudinales (Fig. 4: 7 y 8) y transversales (Fig. 4: 5). Estos últimos están destinados bien a la limpieza de la tabla de accidentes de talla, bien a la reactivación del cintrado del núcleo, que en los transversales cambia el sentido de la talla. También se han documentado dos lascas de avivado de raspador carenado.

El número de desechos de talla es muy reducido $(4,2 \%)$, probablemente, como venimos apuntando, por las condiciones de excavación del depósito.

\subsubsection{Fase 3 de la cadena operativa. Consumo y abandono}

Está altamente representada e incluye tanto el material configurado como los núcleos agotados (Fig. 2A). Las diferencias tecnológicas de los soportes retocados o clasificados como morfotipos respecto a los soportes brutos son escasas, aunque existen algunos matices significativos. Ya comentamos que la relación entre soportes brutos y retocados en el total del conjunto se inclinaba solo ligeramente hacia el primer grupo (Tab. 2). La situación llega a invertirse en el caso del sílex, ya que el material retocado $(38,3 \%)$ supera los soportes brutos $(36,1 \%)$. Con el cuarzo la tendencia general se acentúa, siendo mayoritarios los soportes no retocados $(51,4 \%)$ frente a los retocados $(24,3 \%)$. La implicación lógica es que el material retocado de todo el conjunto está litológicamente dominado por el sílex $(85,6 \%)$ frente al cuarzo $(13,6 \%)$ y la cuarcita $(0,8 \%)$.

Para la configuración de los morfotipos identificados se utilizan los soportes laminares, más de la mitad del total, seguidos de las lascas, los productos de acondicionamiento, las laminitas y las lascas laminares (Tab. 4). Si discriminamos estos soportes según materias primas, el dominio laminar se mantiene casi invariable, aumentando ligeramente en el sílex $(56,1 \%)$ y apenas disminuyendo en el cuarzo (53\%), que aparece exclusivamente como cristal de roca (Tab. 4). Es por tanto constatable una predilección por los soportes laminares en ambas producciones. Ello sin embargo no impide una configuración relativamente abundante de lascas a partir de soportes brutos y de acondicionamiento, sobre la que realizaremos algunas consideraciones posteriormente.

Conviene destacar también que los soportes retocados presentan los mayores estigmas de preparación de los planos de percusión: el 25,4\% del total del material retocado en sílex y el $11,8 \%$ en cuarzo/cristal de roca.

Contamos con una amplia variedad de morfotipos, identificados a partir de la lista tipológica clásica de Sonneville-Bordes y Perrot (1954, 1955, 1956a, 1956b) algo modificada (Tab. 4). Entre ellos resultan especialmente significativos varios grupos tipológicos (Tab. 5):

Raspadores (20,8\% del material retocado): es el tipo mayoritario, doblando con creces al número de buriles $(9,6 \%)$. Salvo dos casos, se presenta sobre láminas, fundamentalmente de sección espesa pero también sobre morfologías esbeltas, muchas de ellas retocadas (Fig. 5: 1-5 y Fig. 6: 5 y 7$)$.

Escotaduras y denticulados $(17,6 \%)$ : realizados sobre una mayor variedad de soportes, como láminas, lascas y productos de acondicionamiento (Fig. 6: 3).

Puntas de Vale Comprido (10,4\%): es el morfotipo que consideramos aporta una mayor información para la caracterización industrial del conjunto estudiado, ya que es uno de los elementos
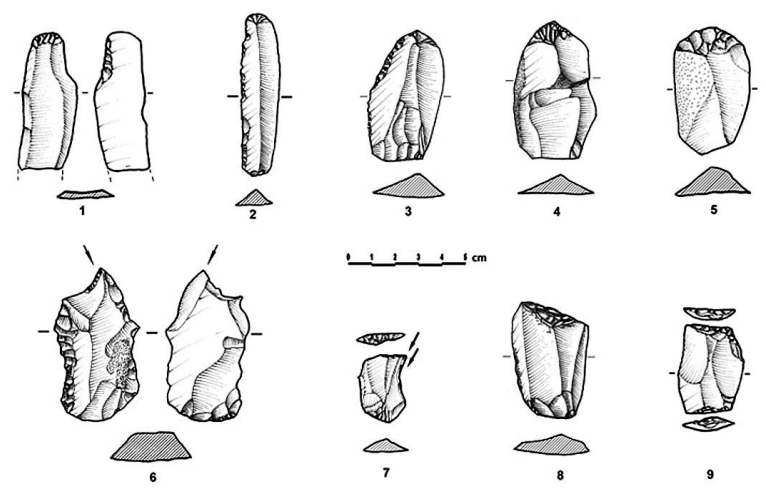

Fig. 5. Soportes retocados del nivel 3 de Peña Capón (valle del Sorbe, Guadalajara). 1-3: raspadores sobre lámina retocada ( 1 con retoques planos inversos: Fig. 6.5., 3 con adelgazamiento en la base); 4 y 5 : raspadores sobre láminas anchas y espesas (4 con adelgazamiento en la base: Fig. 6.7.); 6: denticulado-bec-buril-astillada (Fig. 6.6.); 7: buril sobre truncadura recta; 8-9: piezas astilladas. Todos en sílex excepto 7 en cristal de roca. Dibujos Javier Alcolea. 


\begin{tabular}{|c|c|c|c|c|c|c|}
\hline Tipos y totales & Lámina & Laminita & Lasca & Lasca laminar & Acondic. & Canto \\
\hline 1. Raspador simple $=8$ & 8 & & & & & \\
\hline 2. Raspador atípico $=2$ & 1 & & & & 1 & \\
\hline 5. Raspador sobre lám. retocada $=13$ & $12(1 \mathrm{CR})$ & & & 1 & & \\
\hline 11. Raspador carenado $=1$ & 1 & & & & & \\
\hline 14. Raspador plano en hocico $=1$ & 1 & & & & & \\
\hline 16. Rabot $=1$ & & & & & & $1(\mathrm{CU})$ \\
\hline 23. Perforador $=1$ & 1 & & & & & \\
\hline 27. Buril diedro recto $=3$ & 1 & & 1 & & 1 & \\
\hline 30. Buril de ángulo sobre rotura $=3$ & $2(1 \mathrm{CR})$ & $1 \mathrm{CR}$ & & & & \\
\hline 30b. Buril de ángulo sobre talón $=2$ & & & & & 2 & \\
\hline 34. Buril sobre truncadura recta $=2$ & $1 \mathrm{CR}$ & & $1 \mathrm{CR}$ & & & \\
\hline 37. Buril sobre truncadura convexa $=1$ & & & $1 \mathrm{CR}$ & & & \\
\hline 39. Buril transversal sobre escotadura $=1$ & $1 \mathrm{CR}$ & & & & & \\
\hline 45b. Cuchillo con dorso natural $=1$ & & & & & 1 & \\
\hline 59. Pieza con borde abatido parcial $=2$ & 1 & & 1 & & & \\
\hline 60. Truncadura recta $=2$ & & & & 1 & $1 \mathrm{Q}$ & \\
\hline 61. Truncadura oblicua $=1$ & 1 & & & & & \\
\hline 65. Pieza con retoque continuo sobre un borde $=7$ & 3 & & 1 & & 3 & \\
\hline 66b. Pieza con retoque alterno $=2$ & 2 & & & & & \\
\hline 69b. Punta de Vale Comprido. Subtipo A $=7$ & $5(1 \mathrm{CR})$ & & & 2 & & \\
\hline 69c. Punta de Vale Comprido. Subtipo $C=6$ & $6(2 \mathrm{CR})$ & & & & & \\
\hline 70b. Pieza con retoque plano inverso $=2$ & 1 & & 1 & & & \\
\hline 74. Escotadura $=9$ & $4(1 \mathrm{CR})$ & & $3(2 \mathrm{CR})$ & & 2 & \\
\hline 75. Denticulado $=13$ & $6(1 \mathrm{CR})$ & & $2(1 \mathrm{CR})$ & 1 & 4 & \\
\hline 76. Pieza astillada $=13$ & 6 & & 6 & & 1 & \\
\hline 77. Raedera $=2$ & & & 2 & & & \\
\hline $85 \mathrm{~b}$. Laminita con retoque marginal inverso $=1$ & & 1 & & & & \\
\hline 88. Laminita denticulada $=1$ & & 1 & & & & \\
\hline 90. Laminita Dufour $=1$ & & $1(\mathrm{CR})$ & & & & \\
\hline 90b. Laminita con retoque semi-abrupto $=3$ & & 3 & & & & \\
\hline 92. Diversos $=13$ & 5 & 1 & 3 & 1 & 3 & \\
\hline TOTAL $=125$ & $\begin{array}{c}69 \\
(55,2 \%)\end{array}$ & $\begin{array}{c}8 \\
(6,4 \%)\end{array}$ & $\begin{array}{c}22 \\
(17,6 \%)\end{array}$ & $\begin{array}{c}6 \\
(4,8 \%)\end{array}$ & $\begin{array}{c}19 \\
(15,2 \%)\end{array}$ & $\begin{array}{c}1 \\
(0,8 \%)\end{array}$ \\
\hline
\end{tabular}

Tab. 4. Lista tipológica según categoría tecnológica utilizada como soporte. Acondic. $=$ Acondicionamiento; $\mathrm{CR}=$ Cristal de roca; $\mathrm{Q}=$ Cuarzo; $\mathrm{CU}=$ Cuarcita; Sin especificar = Sílex. Conjunto industrial del nivel 3 de Peña Capón (valle del Sorbe, Guadalajara).

propios, sino un verdadero "fósil director", de lo que se ha definido en la Extremadura portuguesa como Protosolutrense. Aparece sólo de forma testimonial en algunos niveles atribuibles al Solutrense inferior (Zilhão y Aubry 1995; Zilhão 1997: 200; Almeida 2000; Almeida et al. 2010; 
Renard 2010). Su notable presencia en el nivel 3 de Peña Capón es una primera referencia para la caracterización crono-cultural del mismo. Se trata de una serie de 13 piezas, 10 de ellas en sílex y 3 en cristal de roca (Fig. 7), configuradas sobre soportes convergentes, fundamentalmente láminas anchas, que en dos casos entrarían dentro de la categoría de lascas laminares (Fig. 7: 3 y 5), y siempre con talones lisos. La aparición de negativos unidireccionales en los anversos de todas ellas indica que provienen de esquemas de producción unipolares, probablemente organizados a partir de núcleos prismáticos de tabla ancha y tendencia piramidal. Aunque la morfología de los soportes acusa cierta variabilidad, la mayoría presenta una desviación acusada con respecto al eje tecnológico, lo que en algunos casos desemboca en puntas marcadamente disimétricas (Fig. 7: 2 y 4). Las puntas de Vale Comprido de Peña Capón han sido obtenidas mediante percusión dura, como indicaría el espesor de los talones. Sin embargo, como ya adelantamos, en algunas encontramos estigmas como bulbos difusos, escamas bulbares longitudinales y talones ligeramente labiados, que anuncian el uso de percusión de piedra blanda.

Mención especial merecen los negativos de levantamientos cortos en el sector proximal del anverso, atributo propuesto como elemento definitorio de este tipo de puntas, y cuya posición cronológica en la cadena gestual de producción ha sido objeto de discusión en los diferentes sitios donde se ha identificado este morfotipo (Zilhão y Aubry 1995; Zilhão et al. 1999; Renard 2010). Los autores citados llegan a la conclusión de que estos negativos corresponderían a levantamientos posteriores a la extracción del soporte, pudiendo por tanto considerarse retoques en sentido estricto. Para ello se basan en que algunos negativos provienen del retoque lateral de los filos, así como en la existencia de soportes similares en un mismo nivel con talones más espesos (y que por tanto no habrían sido objeto de una reducción mediante retoque). A estos argumentos recientemente se han sumado los resultados preliminares obtenidos por Almeida et al. (2010) en el taller al aire libre de Portela 2 (Leiria, Extremadura portuguesa), donde los remontajes identificados parecen indicar un retoque in situ de estos productos. En Peña Capón la situación es más compleja, pues aunque en algunas piezas sí hemos identificado negativos que provienen de los filos de la pieza y no de

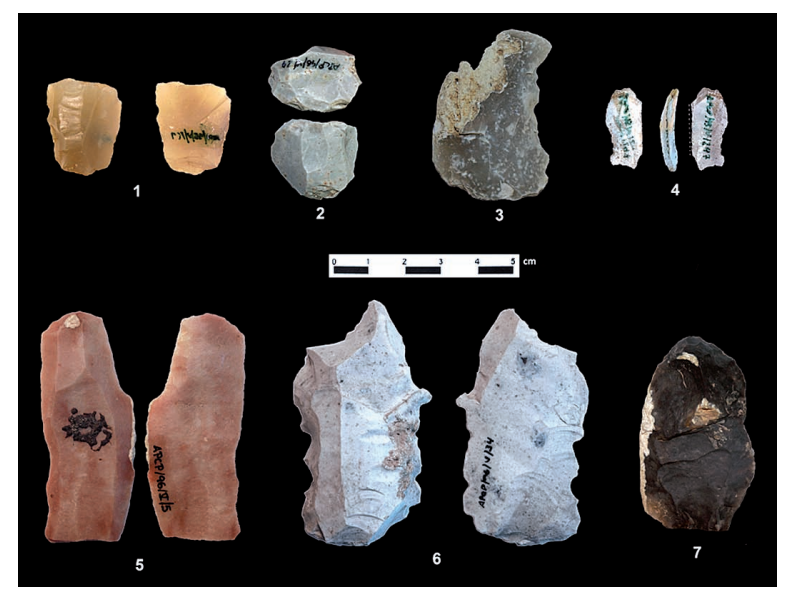

Fig. 6. Industria lítica del nivel 3 de Peña Capón (valle del Sorbe, Guadalajara). 1: núcleo-bipolar-pieza astillada (Fig. 4.4); 2: núcleo de laminitas piramidal unipolar (Fig. 4.3); 3: denticulado sobre lasca centrípeta; 4: laminita Dufour (Fig. 4.9); 5: raspador con retoque plano inverso (Fig. 5.1); 6: útil múltiple/reutilizado (Fig. 5.6); 7: raspador con base adelgazada (Fig. 5.4). Fotografías Manuel Alcaraz-Castaño y Elizabeth Díaz.

la base (Fig. 7: 1 y 8), en otras los negativos son cortados por la propia extracción del soporte (Fig. 7: 3 y 5), lo que indica su anterioridad con respecto a este. Se trataría pues, al menos en este último grupo, de negativos correspondientes a la preparación del plano de percusión, cuyo objetivo sería reducir la cornisa. En cualquier caso, nuestra opinión es que la anterioridad o posterioridad de estas extracciones es una cuestión que solo altera la secuencia gestual de producción, pero no su finalidad, centrada en la fabricación de puntas con el sector proximal adelgazado. Ello probablemente facilitaría el enmangue de las mismas y su uso como proyectiles, tal como han propuesto Zilhão y Aubry (1995) o Renard (2010). En este sentido, es llamativo que haya negativos similares a los de la base de estas puntas en otras piezas de la colección, entre ellas dos raspadores, para los que sin embargo no es posible determinar la anterioridad o posterioridad de las extracciones (Fig. 5: 3 y 4 y Fig. 6: 7). De estas puntas de Vale Comprido 7 fueron configuradas sin más modificación que la de la base (ya sea ésta anterior o posterior a la extracción del soporte). Corresponden pues al subtipo A definido por Zilhão y Aubry (1995: 134) (Fig. 7: 4-8). Otros 6 ejemplares se encuadran en el subtipo $\mathrm{C}$, pues en la zona distal de uno 

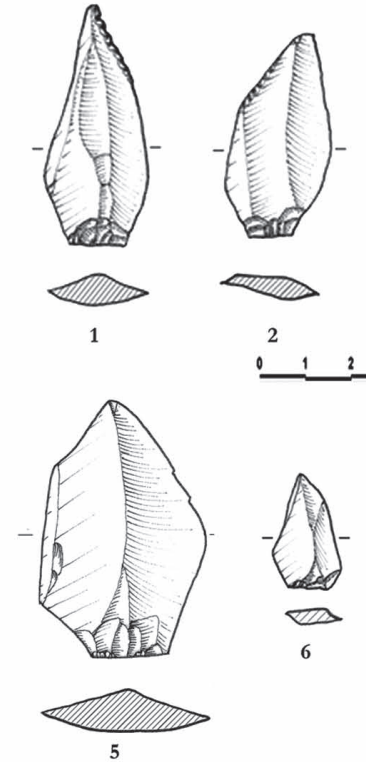

2
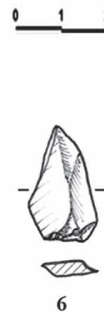
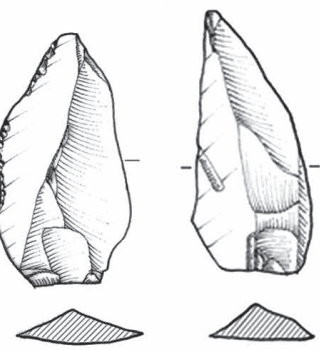

3
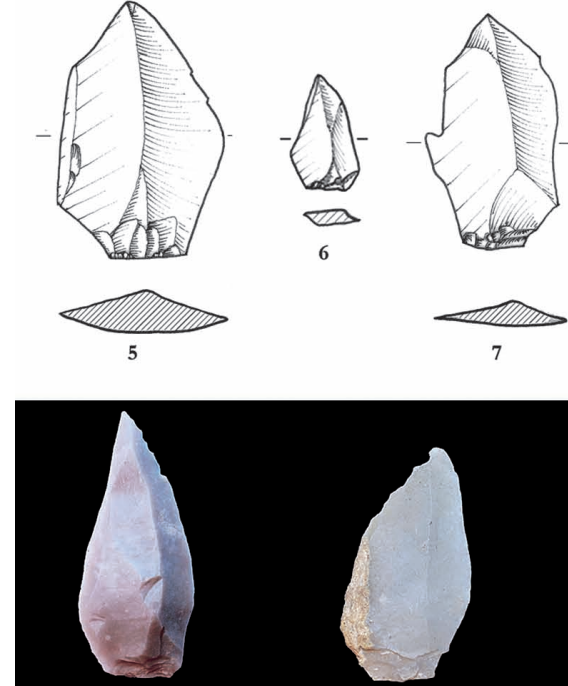

1

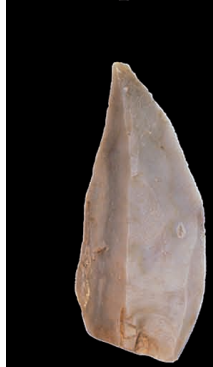

4

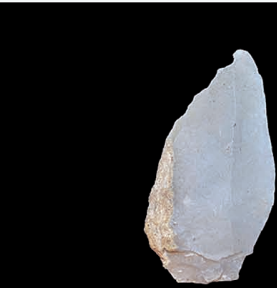

2
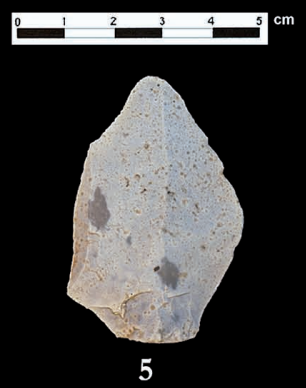

5

Fig. 7. Puntas de Vale Comprido del nivel 3 de Peña Capón (valle del Sorbe, Guadalajara). Todas en sílex excepto la 6 en cristal de roca. Dibujos Javier Alcolea. Fotografías Manuel Alcaraz-Castaño y Elizabeth Díaz.

de sus filos presentan retoques simples (Fig. 7: 3) y en algunos casos semi-abruptos (Fig. 7: 1-2), que configuran el ápice de la pieza.

Piezas astilladas $(10,4 \%)$ : constituyen otro de los grupos industriales significativos del nivel estudiado. Abundan en diversos contextos gravetienses peninsulares (Peña 2009) y aparecen también en algunos niveles protosolutrenses de la Extremadura portuguesa (Aubry et al. 1997). La interpretación funcional del morfotipo presenta una problemática específica, que bascula entre su definición como "útil intermedio" tipo cuña o como núcleo bipolar para la obtención de laminitas (Peña 2011). A falta de un programa experimental que nos permita contextualizar las piezas astilladas del nivel 3 de Peña Capón en esta discusión, podemos avanzar que no asumimos su caracterización unívoca. Por un lado, hemos identificado 13 piezas que responden a criterios morfotécnicos válidos para considerarlas cuñas o elementos intermedios de percusión, tales como un tamaño y espesor considerable o la ausencia de negativos claros de extracciones posteriores a la obtención del soporte (Fig. 5: 8-9). Por otro lado hemos reconocido 3 piezas astilladas con negativos bipolares en sus anversos, y en menor medida sus reversos, así como al menos uno de los extremos regularizado a modo de plano de percusión. Estas características indican su probable papel como núcleos de laminitas (Fig. 4: 4 y Fig. 6: 1), tal como se ha propuesto en otros yacimientos gravetienses y protosolutrenses portugueses (Aubry et al. 1997).

Apoyaría además esa interpretación la presencia en la colección de varias laminitas de tipo astilla, con sección trapezoidal y talón astillado (Fig. 4: 10), cuya producción a partir de este tipo de piezas es más que probable. Siguiendo esta interpretación, únicamente hemos contabilizado como morfotipos las piezas astilladas clasificadas como útiles intermedios. Estas piezas son las responsables del alto índice de talones suprimidos ya comentado para los soportes retocados (Fig. 3A), ya que el astillamiento de los extremos del soporte suele provocar la supresión del talón.

Laminitas: su porcentaje es significativo entre el material retocado $(6,4 \%)$ y los soportes brutos $(19,4 \%)$. Destaca una en cristal de roca con retoque inverso, que entraría en el morfotipo de laminita Dufour, y cuya curvatura y morfología podrían indicar su procedencia de un núcleo de tipo raspador carenado (Fig. 4: 9 y Fig. 6: 4).

Piezas con retoque plano: no se individualizan como grupo tipológico si no por su gran interés para profundizar en la caracterización cronocultural de la industria, al denotar la presencia incipiente de un recurso técnico básicamente solutrense, también latente en el Protosolutren- 


\begin{tabular}{|l|c|c|}
\hline & Total & \% \\
\hline Raspadores & 26 & 20,8 \\
\hline Perforadores & 1 & 0,8 \\
\hline Buriles & 12 & 9,6 \\
\hline Piezas de dorso & 3 (1 natural) & 2,4 \\
\hline Truncaduras & 3 & 2,4 \\
\hline Piezas con retoque lateral & 11 & 8,8 \\
\hline Puntas de Vale Comprido & 13 & 10,4 \\
\hline Escotaduras y denticulados & 22 & 17,6 \\
\hline Piezas astilladas & 13 & 10,4 \\
\hline Raederas & 2 & 1,6 \\
\hline Laminitas & 6 & 4,8 \\
\hline Diversos & 13 & 10,4 \\
\hline TOTAL & 125 & 100 \\
\hline
\end{tabular}

Tab. 5. Grupos tipológicos identificados en el conjunto industrial del nivel 3 de Peña Capón (valle del Sorbe, Guadalajara).

se portugués (Zilhão et al. 1999: 171). Además, en su gran mayoría estos retoques se asocian a morfotipos específicos como 4 raspadores sobre lámina (Fig. 5: 1 y Fig. 6: 5) y 1 buril sobre lasca, todos de dirección inversa. Completan el grupo 1 lámina con retoque lateral plano directo, 1 lasca con retoques planos y bifaciales y 1 lasca sobrepasada de avivado o reducción que arrastra una cara con retoques planos.

Finalizamos la fase de consumo y abandono con algunas consideraciones sobre los 17 núcleos presentes en el nivel (4,8\% de la muestra) (Tab. 2). Los núcleos de laminitas son los mejor representados $(64,8 \%)$ (Tab. 6), frente a los de láminas $(11,8 \%)$, lascas $(11,8 \%)$ e indeterminados $(11,8 \%)$. Esta circunstancia, que supone un contrapunto al dominio de los soportes laminares y lascares frente a las laminitas, dificulta caracterizar las producciones de láminas. Agrava esta cuestión que los dos únicos núcleos laminares identificados correspondan a fragmentos poco informativos, de los que solo se puede inferir su organización unipolar.

Los núcleos de laminitas analizados caracterizan mejor las matrices de obtención de estos soportes. Entre los de gestión unipolar, han sido documentadas las morfologías prismáticas (cristal de roca) y piramidales (sílex) (Fig. 4: 3 y Fig. 6: 2), así como

\begin{tabular}{|c|c|c|c|}
\hline Método & Sílex & $\begin{array}{l}\text { Cuarzo/ } \\
\text { Cristal } \\
\text { de roca }\end{array}$ & Total \\
\hline $\begin{array}{l}\text { Laminitas - } \\
\text { prismático } \\
\text { unipolar }\end{array}$ & & 2 & 2 \\
\hline $\begin{array}{l}\text { Laminitas - } \\
\text { piramidal } \\
\text { unipolar }\end{array}$ & 2 & & 2 \\
\hline $\begin{array}{l}\text { Laminitas - } \\
\text { Raspador } \\
\text { carenado }\end{array}$ & 1 & 1 & 2 \\
\hline $\begin{array}{l}\text { Laminitas } \\
\text { oportunista } \\
\text { (multi- } \\
\text { direccional) }\end{array}$ & 2 & & 2 \\
\hline $\begin{array}{c}\text { Núcleo bipolar } \\
- \\
\text { Pieza astillada }\end{array}$ & 3 & & 3 \\
\hline $\begin{array}{l}\text { Láminas - } \\
\text { indeterminado } \\
\text { unipolar }\end{array}$ & 2 & & 2 \\
\hline $\begin{array}{c}\text { Lascas - } \\
\text { indeterminado }\end{array}$ & 2 & & 2 \\
\hline Indeterminado & 1 & 1 & 2 \\
\hline Total & $\begin{array}{c}13 \\
(76,5 \%)\end{array}$ & $\begin{array}{c}4 \\
(23,5 \%)\end{array}$ & 17 \\
\hline
\end{tabular}

Tab. 6. Núcleos identificados en el conjunto industrial del nivel 3 de Peña Capón (valle del Sorbe, Guadalajara).

los núcleos de tipo raspador carenado (1 en sílex, 1 en cuarzo) (Fig. 4: 1-2). La entidad en la colección de estos últimos se ve reforzada por la presencia de 2 lascas de avivado de frente de raspador, que arrastran parte de la tabla microlaminar. Como ya expusimos, 3 piezas astilladas han sido catalogadas como núcleos bipolares para la extracción de lasquitas y laminitas probablemente mediante la percusión posada sobre yunque (Fig. 4: 4 y Fig. 6: 1).

\subsubsection{Esquemas operativos y atribución industrial}

La colección estudiada, aunque reducida, permite una caracterización fundamental de las modalidades y objetivos de los esquemas de talla desarrollados por el grupo o grupos humanos responsables del conjunto industrial. 
Producción de láminas: El predominio de soportes laminares entre los elementos sin retocar $\mathrm{y}$, sobre todo, los retocados, permite identificar la producción de láminas como uno de los objetivos fundamentales de los procesos de talla desarrollados en la ocupación del nivel 3. La variedad morfológica de las láminas indica una relativa diversidad tecnológica (Fig. 5), que incluye gestiones mayoritariamente unipolares, pero también bipolares. Sin embargo, la ausencia de núcleos laminares significativos nos impide describir con mayor precisión los esquemas operativos implicados en esta producción.

Por la importancia que hemos otorgado a las 13 puntas de Vale Comprido en la caracterización del nivel estudiado, consideramos de especial relevancia valorar las características tecnológicas de su producción basándonos en los soportes sobre los que han sido configuradas. El esquema de producción de este morfotipo ha sido convenientemente identificado en los yacimientos protosolutrenses de la Extremadura portuguesa (Zilhão y Aubry 1995; Zilhão 1997: 204; Zilhão et al. 1999), y más recientemente en el sitio francés de Marseillon (Landas), asignado al mismo episodio industrial (Renard 2010). En ambos casos, los núcleos y soportes estudiados proponen esquemas de producción a partir de núcleos prismáticos de tabla ancha y tendencia piramidal, gestionados mediante percusión dura desde un único plano de percusión sin preparación. Como hemos comentado, no disponemos en Peña Capón de núcleos que respondan a estas características. Sí se adaptan sin problemas a las mismas los soportes de las puntas de Vale Comprido documentadas (Fig. 7) $\mathrm{y}$, probablemente, los 3 flancos de núcleo identificados, dos longitudinales (Fig. 4: 7-8) y uno transversal (Fig. 4: 5), que presentan negativos de extracciones anchas, unipolares, y en algún caso convergentes.

Los soportes de las 3 puntas de Vale Comprido realizadas sobre cristal de roca son notablemente más pequeños (25,3 long. x 16,7 anch. x 5,8 esp. mm de media) (Fig. 7: 6) que los fabricados en sílex (48,7 long. x 27,7 anch. x 7,4 esp. mm de media), lo que implicaría una más que probable diferencia funcional. La interpretación de unas y otras como puntas de armas arrojadizas, asumible en las de mayor tamaño y discutible en las más pequeñas, exige un programa experimental aún sin realizar. Por lo tanto, nos limitamos aquí a señalar la adaptación de un esquema operativo que se utiliza de forma recurrente sobre sílex a las características morfométricas del cuarzo/cristal de roca. La escasez de elementos correspondientes a las fases iniciales de la talla en una y otra materia prima nos impide ir más allá en la comparación entre ambas producciones. Sin embargo, algunas superficies corticales en lascas de cuarzo y cristal de roca nos informan de que las matrices explotadas en esta materia prima debieron presentarse en forma de cantos, probablemente de tamaño medio y pequeño, similares a los documentados en el sitio extremeño portugués de Lapa do Anecrial (Zilhão et al. 1997: 300).

Con estos datos, resulta pertinente concluir que las puntas de Vale Comprido, y en general los elementos retocados sobre lámina, fueron mayoritariamente introducidos en el abrigo ya finalizados, o a lo sumo fueron configuradas en él a partir de soportes brutos obtenidos en otro lugar. Sin embargo, los elementos de acondicionamiento relacionados con los esquemas de producción de puntas indicarían actividades de talla in situ, quizá esporádicas, destinadas a la obtención de soportes, cuyos núcleos sin embargo no habrían sido abandonados en el abrigo.

Producción de laminitas: en contraste con la talla laminar, la relativa abundancia de núcleos de laminitas, aun con escasos soportes documentados, nos permite certificar la producción microlaminar en el yacimiento. Está realizada a partir de cuatro esquemas operativos: prismático unipolar, piramidal unipolar, raspador carenado y núcleo bipolar-pieza astillada (Tab. 6). Esta heterogeneidad tecnológica permite abundar en las similitudes con los conjuntos protosolutrenses, para los que se ha definido una variabilidad de esquemas operativos semejante. Especialmente relevantes en este sentido son las producciones a partir de raspadores carenados y de piezas astilladas, identificadas en los sitios portugueses (Zilhão y Aubry 1995; Aubry et al. 1997; Zilhão et al. 1999) y del Suroeste francés (Aubry et al. 1995; Renard 2010). La caracterización de las laminitas en los citados sitios protosolutrenses, donde se dejan fundamentalmente sin retocar o, en menor medida, se configuran mediante retoque simple (Zilhão et al. 1999: 175-176), encuentra un paralelo claro en el nivel 3 de Peña Capón, donde la mayoría se presentan en estado bruto $(81,8 \%)$. Entre las que tienen retoques simples $(18,2 \%)$ destaca una 
Dufour en cristal de roca obtenida probablemente a partir de un raspador carenado (Fig. 4: 9 y Fig. 6:4). La elevada presencia de núcleos y soportes en cuarzo y cristal de roca (Tabs. 3 y 6) es otra similitud importante con el Protosolutrense de la Extremadura portuguesa, donde la producción de laminitas en cuarzo alcanza porcentajes notables en varios yacimientos (Zilhão et al. 1997).

Producción de lascas: hemos documentado un importante número de lascas en el nivel (Tabs. 3 y 4), al que se suman dos núcleos que sin embargo son poco informativos sobre su método de gestión específico. Solo 3 de los 71 soportes lascares entre brutos y retocados exhiben los atributos característicos de los esquemas operativos discoides (Terradas 2003), por lo que resulta aventurado proponer una producción específica de lascas. Es más plausible que dichos soportes se enmarquen en las fases de preparación y acondicionamiento de la talla laminar. Sin embargo, que haya un denticulado configurado sobre una lasca con negativos centrípetos y de un sílex poco frecuente en la colección (Fig. 6: 3), nos conduce a ser prudentes y no descartar la existencia de un esquema operativo de producción de lascas destinado a la configuración de este tipo de utillaje.

Los resultados obtenidos en el estudio tipológico y tecnológico de la colección lítica indican que el nivel 3 de Peña Capón, lejos de pertenecer a los momentos iniciales del Paleolítico Superior como se había conjeturado inicialmente (Alcolea et al. 1997), debe relacionarse con las industrias protosolutrenses definidas en la Extremadura portuguesa. Las puntas de Vale Comprido, los incipientes retoques planos, la producción de laminitas a partir de raspadores carenados y núcleos bipolares, así como la explotación significativa del cuarzo, bastan para atribuir la colección industrial analizada al Protosolutrense. En la sección de discusión incidiremos en la caracterización y problemática actual de este episodio industrial.

\subsection{Zooarqueología y tafonomía de los restos faunísticos}

La fauna conservada en el nivel 3 de Peña Capón comprende 564 restos. Se han podido identificar 4 ciervos, 2 cabras, 1 caballo y 1 gran bóvido, del que no se puede precisar si es uro o bisonte.
Entre los micromamíferos se han documentado algunos restos de lagomorfo, 6 identificados como conejos. Entre los indeterminados dominan los animales de talla media (ciervo, asno, etc.) sobre los de talla grande (uro, caballo, etc.) y pequeña (cabra, rebeco, corzo, etc.) (Tab. 7). Por tanto, el perfil taxonómico del conjunto, aunque dominado por el ciervo, es heterogéneo, coexistiendo animales de distintos tamaños y ecosistemas diferentes.

La contextualización y comparación del conjunto faunístico resulta complicada. La falta de yacimientos del Paleolítico Superior con fauna anteriores al Tardiglaciar en la Meseta (Yravedra 2007) impide realizar comparaciones en el ámbito regional, y la práctica ausencia de restos óseos en los yacimientos del Protosolutrense portugués, utilizados como marco de referencia en el terreno industrial, imposibilita su contextualización en un marco interpretativo más amplio. Así las cosas, únicamente podemos constatar que la composición heterogénea del nivel 3 de Peña Capón encuentra similitudes en los patrones taxonómicos documentados en varios sitios del Gravetiense Terminal de la Extremadura portuguesa, como Lagar Velho TP06 (Moreno García y Pimenta 2002) y Unidad EE15 (Almeida et al. 2009). En ellos, un registro faunístico variado denota una explotación cinegética indiferenciada, posiblemente ligada a la existencia de nichos ecológicos diversos. La pauta se repite en numerosos niveles del Gravetiense peninsular, tanto en la vertiente cantábrica (Straus 1992; Yravedra 2001; Yravedra y GómezCastanedo 2010), como mediterránea (Davidson 1989; Villaverde et al. 2007-2008), donde los yacimientos con conjuntos faunísticos heterogéneos son mayoritarios.

En los patrones de mortandad, aunque la muestra está dominada por los individuos adultos, destacamos una cabra y un ciervo infantiles, así como un ciervo juvenil. Valoramos la hipótesis de que estos datos puedan apuntar a un tipo de explotación preferencial sobre manadas de hembras con crías, tal como se ha indicado en otros lugares (Altuna 1986), pero lo escaso de la muestra nos impide establecer conclusiones definitivas a este respecto.

Desde una perspectiva tafonómica, estamos ante un conjunto en buen estado de conservación, con gran fracturación y claras evidencias de una importante actividad antrópica. Las elevadas frecuencias de huesos con marcas de corte y per- 


\begin{tabular}{|c|c|c|c|c|}
\hline Taxón & NR & $\%$ & $\begin{array}{l}\text { MNI } \\
\text { A/J/I }\end{array}$ & $\%$ \\
\hline Equus & 18 & 3,2 & 1 & 6,7 \\
\hline Bos-Bison & 2 & 0,4 & 1 & 6,7 \\
\hline Cervus & 117 & 20,7 & $2 / 1 / 1$ & 26,7 \\
\hline Capra & 11 & 2,0 & $2 / 0 / 1$ & 20 \\
\hline Grande & 56 & 9,9 & & \\
\hline Mediano & 70 & 12,4 & & \\
\hline Pequeño & 52 & 9,2 & & \\
\hline Indet. & 189 & 33,5 & & \\
\hline Lagomorfo & 49 & 8,7 & 6 & 40 \\
\hline Total & 564 & & 15 & 100 \\
\hline
\end{tabular}

\begin{tabular}{|l|c|c|c|c|c|c|}
\hline & \multicolumn{2}{|c|}{$\begin{array}{c}\text { Marcas } \\
\text { Corte }\end{array}$} & \multicolumn{2}{c|}{$\begin{array}{c}\text { Marcas } \\
\text { Percusión }\end{array}$} & \multicolumn{2}{c|}{$\begin{array}{c}\text { Marcas } \\
\text { Diente }\end{array}$} \\
\hline \multicolumn{1}{|c|}{ Taxón } & NR & \% & NR & \% & NR & \% \\
\hline Equus & 8 & 44,4 & 3 & 16,7 & 2 & 11,1 \\
\hline Cervus & 29 & 24,8 & 18 & 15,4 & 3 & 2,6 \\
\hline Capra & 2 & 18,2 & 1 & 9,1 & 1 & 9,1 \\
\hline Grande & 10 & 17,9 & 6 & 10,7 & & \\
\hline Mediano & 9 & 12,9 & 5 & 7,1 & 6 & 8,6 \\
\hline Pequeño & 9 & 17,3 & 3 & 5,8 & 2 & 3,8 \\
\hline Indet. & 1 & 0,5 & 2 & 1,1 & 2 & 1,1 \\
\hline Lagomorfo & 4 & 8,2 & 2 & 4,1 & 6 & 12,2 \\
\hline Total & 72 & 12,8 & 40 & 7,1 & 26 & 4,6 \\
\hline
\end{tabular}

Tab.7. Perfiles taxonómicos del conjunto faunístico del nivel 3 de Peña Capón (valle del Sorbe, Guadalajara) distribuidos en NR (Número de restos) y MNI (Mínimo número de individuos). A: Adulto; J: Juvenil; I: Infantil; Indet.: Indeterminado.

cusión nos indican que todos los taxones fueron procesados por el ser humano (Tab. 8). Caballos, ciervos y cabras muestran trazas relacionadas con episodios de desollado, eviscerado, desarticulado y descarnado, culminando la cadena alimenticia con la fracturación de los huesos para obtener su tuétano. Algunas marcas de diente, cuyas medidas nunca exceden los $2 \mathrm{~mm}$ de longitud y anchura, así como la escasez de epífisis respecto a las diáfisis (Tab. 9), revelan que en determinados episodios, probablemente al abandonarse el yacimiento, carnívoros de pequeño tamaño, como por ejemplo el zorro, podrían haber manipulado parte de los restos óseos. El cierto sesgo que produjeran en la muestra en ningún caso cuestiona el carácter antrópico de la gran mayoría de la acumulación ósea.

\begin{tabular}{|l|c|c|c|}
\hline & \multicolumn{3}{|c|}{ Epp/Dia/Epd } \\
\hline & Superior & Medial & Inferior \\
\hline Grande & $0 / 17 / 0$ & $0 / 12 / 0$ & $0 / 6 / 0$ \\
\hline Mediano & $0 / 45 / 0$ & $0 / 22 / 0$ & $0 / 12 / 1$ \\
\hline Pequeño & $0 / 3 / 0$ & $0 / 3 / 0$ & $0 / 2 / 0$ \\
\hline
\end{tabular}

Tab. 9. Número de restos (NR) de diáfisis (Dia) y epífisis (Epp para la proximal y Epd para la distal) del conjunto faunístico del nivel 3 de Peña Capón (valle del Sorbe, Guadalajara).

Tab. 8. Patrones tafonómicos del conjunto faunístico del nivel 3 de Peña Capón (valle del Sorbe, Guadalajara). NR: Número de restos. Indet.: Indeterminado.

Además de estas evidencias, ya de por sí resolutivas, hemos calculado las frecuencias de marcas de corte en elementos apendiculares superiores, intermedios e inferiores. Estas frecuencias, dominadas por las marcas en el primer grupo (húmero y fémur) en animales grandes y medianos (Tab. 10), se ajustan a las observaciones experimentales de Domínguez-Rodrigo (1997) y Domínguez-Rodrigo y Barba (2005) realizadas para accesos antrópicos primarios sobre carcasas. Según ellas, estas porciones anatómicas, al ser las que conservan mayores paquetes musculares, son las primeras en consumirse en accesos tempranos.

Con estos datos, resulta plausible interpretar la acumulación ósea del nivel 3 de Peña Capón como el producto de la actividad cinegética de los grupos humanos responsables del conjunto industrial asociado. Dicha actividad incluiría desde la caza de los animales en las proximidades del sitio, hasta el posterior procesado de las presas,

\begin{tabular}{|l|c|c|c|c|c|c|}
\hline & Superior & $\mathbf{\%}$ & Medial & $\mathbf{\%}$ & Inferior & $\mathbf{\%}$ \\
\hline Grande & 5 & 29,4 & 2 & 16,7 & 1 & 16,7 \\
\hline Mediano & 17 & 37,8 & 5 & 22,7 & 2 & 16,7 \\
\hline Pequeño & 1 & 33,3 & 2 & 66,7 & 1 & 50,0 \\
\hline
\end{tabular}

Tab. 10. Frecuencias de marca de corte en elementos apendiculares del conjunto faunístico del nivel 3 de Peña Capón (valle del Sorbe, Guadalajara). Superior: húmero y fémur. Medial: tibia y radio. Inferior: metápodos. 
ya en el abrigo. La elevada presencia de puntas de Vale Comprido y la basculación del conjunto del material lítico hacia las fases de consumo de la cadena operativa apoyan esta interpretación.

Por otro lado, la colección faunística del nivel 3 ha proporcionado algunos elementos de industria ósea. Destacan un punzón sobre diáfisis de pequeño tamaño configurado mediante el pulimento de uno de sus extremos (Fig. 8: 2), y una diáfisis de animal de talla media que, a tenor de lo inferido mediante experimentación (Patou-Mathis 2002; Mozota 2009), fue utilizada como retocador de elementos líticos. Así lo indican los estigmas de percusión (impresiones lineales, cúpulas y raspado) en ambos extremos (Fig. 8: 1). También se han documentado algunos restos de grabados incisos en diversos soportes óseos, en ningún caso figurativos. Presentamos un ejemplo en el que se observan varios trazos lineales (Fig. 8: 3).

\section{DISCUSIÓN Y CONCLUSIONES}

\subsection{La aparición del Solutrense en el interior de la Península Ibérica en el contexto del Protosolutrense del Suroeste europeo}

El Protosolutrense es una unidad de análisis historiográficamente con importantes problemas de definición y caracterización industrial. Las primeras propuestas sobre su contenido, realizadas en la primera mitad del siglo XX por A. Parat, H. Breuil, D. Peyrony o A. Cheynier, eran contradictorias (Rasilla 1994: 12, 1999: 81-82) $\mathrm{y}$ probablemente han de situarse en la base de posteriores adscripciones a este episodio industrial ciertamente débiles y problemáticas. Así, las asignaciones al Protosolutrense de niveles como Beneito B6 (Iturbe et al. 1993: 59-61) o Reclau Viver E (Soler y Maroto 1998: 302) informan poco sobre las características de esta industria y han sido muy cuestionadas (Rasilla 1999: 82-83; Villaverde y Román 2004: 39 y 50).

Desde finales de los 1980, la caracterización del Protosolutrense como un episodio industrial definido comenzó a adquirir una mayor entidad a partir del estudio de series líticas provenientes de yacimientos de la región extremeña portuguesa, como el sitio al aire libre de Vale CompridoEncosta o las cuevas de Caldeirão, Buraca Grande o Buraca Escura, entre otros (Zilhão 1997; Zilhão y Aubry 1995; Zilhão et al. 1997, 1999; Almeida 2000). Se definió así una industria, que se entendía inmersa en un proceso de transición entre el Gravetiense y el Solutrense, y que introducía un cambio en el armamento cinegético fundamentado en la sustitución de los proyectiles armados con las laminitas de dorso típicas del Gravetiense, por otros basados en las puntas líticas de Vale Comprido. La producción de laminitas obtenidas a partir de núcleos de tipo raspador carenado y dejadas mayoritariamente sin retocar, así como una explotación significativa del cuarzo, completaron los elementos tecno-tipológicos principales del Protosolutrense portugués. Su cronología, una vez individualizado el Gravetiense Terminal como una fase independiente (Almeida 2000), quedó situada en un corto lapso de tiempo entre c. 21.5 - 21.0 ka C14 BP. Junto a las colecciones líticas portuguesas, los mencionados autores incluyeron en el Protosolutrense las industrias de los niveles NA10 y NA9 del Abri Casserole, así como aquella del clásico Auriñaciense V de LaugerieHaute (niveles D Oeste y 33 Este), ambos en la Dordoña francesa (Aubry et al. 1995; Bosselin y Djindjian 1997). Con ello acabaron de configurar un modelo que, basado en una lectura evolutiva de la tecnología lítica, propone una transición in situ del Gravetiense al Solutrense en el Suroeste europeo, materializada en un Protosolutrense que tiene tanto pervivencias tecnológicas del primero como innovaciones que anuncian el segundo (Zilhão 1997: 201; Zilhão et al. 1999: tab. 1). La principal pervivencia gravetiense serán las minoritarias producciones laminares gestionadas mediante percusión blanda. Las novedades serían la aparición testimonial del retoque plano y, sobre todo, la producción de puntas de Vale Comprido, interpretada como el germen del posterior desarrollo de las puntas de cara plana del Solutrense inferior y, en general, de la predilección por las puntas líticas durante el Solutrense (Zilhão 2007; Renard 2011).

El modelo propuesto presentaba una enorme laguna geográfica entre la Extremadura portuguesa y la Dordoña, para la que Zilhão et al. (1999: 182) predecían una secuencia similar. En los últimos años, esta laguna se ha matizado, si bien los hallazgos de mayor relevancia se han producido en regiones cercanas a los núcleos extremeño y perigordino, cuando no en su propio seno. Así, se 


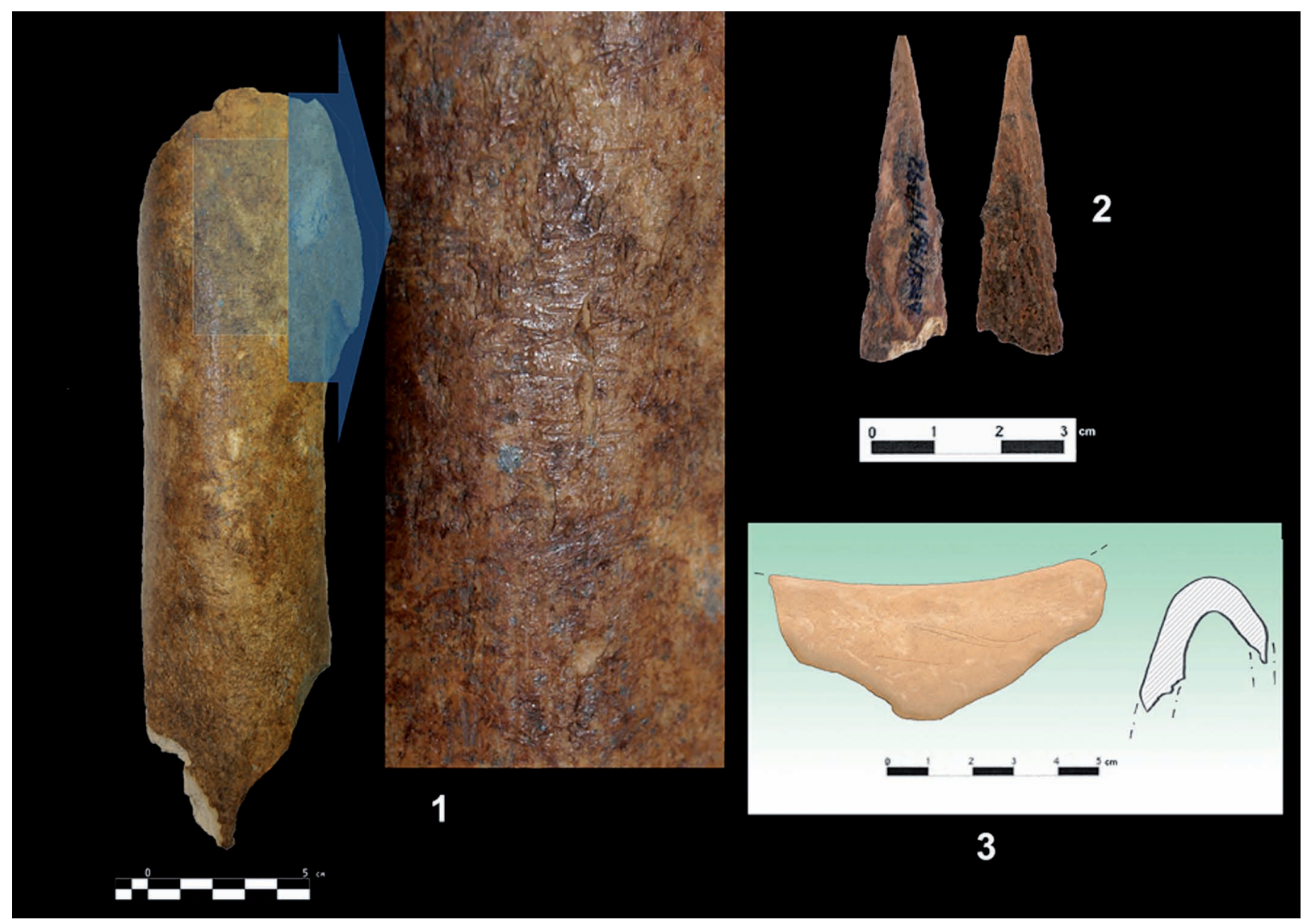

Fig. 8. Industria ósea y elemento decorado del nivel 3 de Peña Capón (valle del Sorbe, Guadalajara). 1: retocador sobre diáfisis con dos zonas activas y detalle de impresiones lineales, cúpulas y raspado en una de ellas; 2: punzón; 3: fragmento de diáfisis con varios trazos lineales grabados. Fotografías Manuel Alcaraz-Castaño y Elizabeth Díaz.

han identificado de forma inequívoca industrias protosolutrenses con puntas de Vale Comprido en el yacimiento al aire libre de Marseillon (Landas) (Renard 2010, 2011), en el abrigo de Vale Boi (Algarve) (Bicho et al. 2010; Cascalheira et al. 2010) y, de nuevo en la Extremadura portuguesa, en los sitos al aire libre de Portela 2 y Calvaria 2 (Almeida et al. 2010).

Otras referencias menos significativas provienen de la región mediterránea peninsular. Aquí se ha apuntado un posible nivel protosolutrense en Balma de la Griera (Tarragona) (García Díez y Cebrià 2003) y se han señalado niveles con puntas de cara plana atípicas y laminitas obtenidas de núcleos carenados en niveles intermedios entre el Gravetiense y el Solutrense en Parpalló (Valencia) (Tiffagom et al. 2007) y Nerja (Málaga) (Aura et al. 2006; Tiffagom et al. 2007). Sin embargo, el primer conjunto industrial es poco diagnóstico y carece de las principales características tecno-tipológicas de estas industrias (Fullola et al. 1994). En los dos últimos, los materiales se encuentran aún a la espera de su publicación definitiva, aunque ya se ha señalado la posible concordancia de la secuencia mediterránea con lo ocurrido en Portugal, si bien desde una propuesta conceptual diferente (Aura et al. 2006: 84; Aura et al. 2010: 167). Aún más problemática es una pieza asimilable a las puntas de Vale Comprido localizada en las colecciones antiguas del Arenero de Santiago, en el valle del Manzanares (Madrid), para la que en todo caso no es posible proponer un contexto industrial y crono-estratigráfico adecuado (Baena y Carrión 2002: 99).

Dejando a un lado este último dato, apenas considerado en la literatura científica, el interior 
de la Península Ibérica no ha aportado hasta la fecha ninguna evidencia que permita valorar el modelo transicional propuesto por Zilhão y colegas. Sólo se conocían en sus territorios datos encuadrables en las fases medias y superiores del Solutrense (Alcolea et al. 1997; Baena y Carrión 2006; Cacho et al. 2010), entre los que destacaban los del propio nivel 2 de Peña Capón. Por ello, la atribución al Protosolutrense de la industria del nivel 3 supone una novedad de primer orden en la discusión sobre la aparición del Solutrense en el Suroeste europeo, pues viene a rellenar un extenso vacío, precisamente en un área intermedia entre las regiones con evidencias protosolutrenses conocidas (Fig. 9).

Sin embargo, a pesar de que en el terreno industrial la caracterización como Protosolutrense del nivel 3 de Peña Capón ofrece pocas dudas, en el ámbito temporal la única fecha obtenida hasta ahora (Tab. 1) lo sitúa un milenio después de la cronología mínima aceptada para los yacimientos portugueses (vide supra), e incluso de la Dordoña, para los que se supone una cronología anterior a $20.8 \mathrm{ka} \mathrm{C14} \mathrm{BP}$ a partir de la datación del Solutrense inferior de Laugerie-Haute (Renard 2011: 737). La interpretación correcta de esta situación debe, en nuestra opinión, tener en cuenta dos posibilidades principales: 1) que la aparición del Protosolutrense en la Meseta se produjera de forma tardía con respecto al Suroeste francés y la costa portuguesa, o 2) que una hipotética contaminación de los restos datados haya rejuvenecido la datación obtenida en Peña Capón, como podría indicar la escasa diferencia entre los resultados de los niveles 2 y 3 (Tab. 1; vid. apartado 2.1.). Un nuevo programa de dataciones a partir de muestras pre-tratadas con ultrafiltración, que esperamos poder llevar a cabo en fechas próximas, así como un más que deseado acceso al depósito que nos permita recoger muestras directamente de la estratigrafía, podrán arrojar luz sobre esta disyuntiva, cuyas alternativas son hipotéticamente factibles y no necesariamente excluyentes. Sin embargo, no somos especialmente partidarios de plantear de nuevo la posición retardataria del interior peninsular en referencia a cualquier tipo de fenómeno o desarrollo cultural prehistórico, máxime cuando la fecha del propio nivel 2 de Peña Capón, ciertamente sometida a los mismos problemas que la del nivel 3, se sitúa en momentos más antiguos (Tab. 1) de lo que es común en un conjunto in-

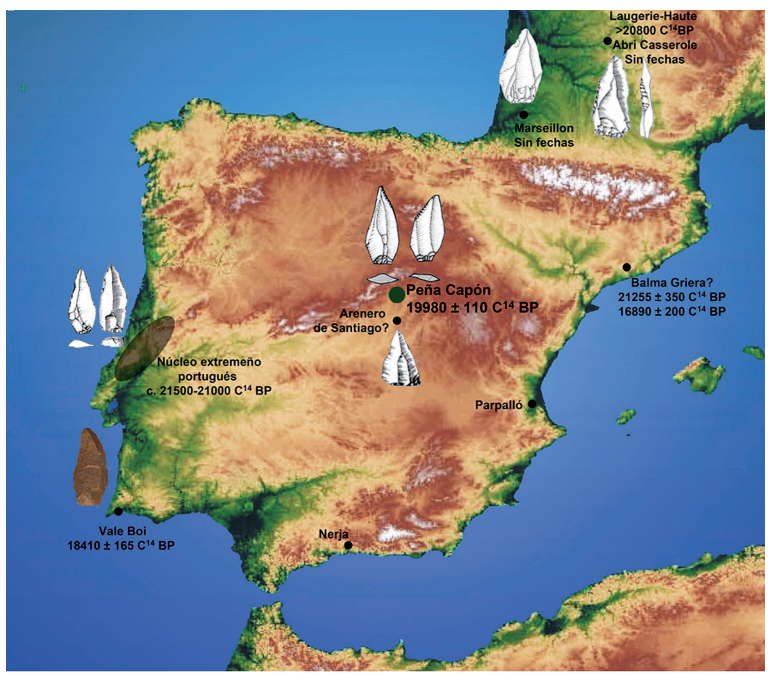

Fig. 9. Distribución de yacimientos con niveles atribuidos al Protosolutrense o presencia de elementos industriales asimilables. Se señalan puntas de Vale Comprido de Caldeirão (Zilhão y Aubry 1995: Fig. 7), Vale Comprido-Encosta (Zilhão y Aubry 1995: Fig. 4), Vale Boi (Cascalheira et al. 2010), Arenero de Santiago (Baena y Carrión 2002: Fig. 4.25), Peña Capón, Marseillon (Renard 2011: Fig. 2.1) y Laugerie-Haute Est (Zilhão y Aubry 1995: Fig. 9).

dustrial cercano a los modelos típicos de las fases medias del Solutrense (Alcolea et al. 1997: 213). Además, valoramos que la secuencia solutrense del interior peninsular está aún por construir, ya que, hasta la fecha, las dataciones realizadas en Peña Capón son las únicas disponibles en la Meseta para niveles de este tecnocomplejo.

La contextualización de los datos aquí presentados en el marco general de las industrias protosolutrenses contribuye a relativizar la importancia de la búsqueda de un origen único para el Solutrense. Su planteamiento en los términos difusionistas propios de la investigación histórico-cultural (Alcaraz-Castaño 2007) ha dejado de tener un sentido efectivo desde una perspectiva científica (Zilhão 2007). Hay una fase industrial anterior al Solutrense inferior en buena parte del territorio de expansión del tecnocomplejo, que además exhibe una homogeneidad tecno-tipológica que se basa en el sustrato Gravetiense a la vez que anuncia el posterior desarrollo del Solutrense. Esta fase supone, a pesar de las críticas recibidas (Straus 1995: 28; Rasilla 1999: 84-85; Tiffagom 2006: 229-231), un fuerte argumento a favor de un modelo de evolución industrial progresivo y

Trab. Prehist., 70, N. ${ }^{\circ}$ 1, enero-junio 2013, pp 28-53, ISSN: 0082-5638

doi: $10.3989 /$ tp.2013.12101 
gradual (Zilhão et al. 1999). Esta evolución parece producirse de forma rápida, si no casi simultánea, en varias regiones, y puede encontrar una explicación verosímil en la existencia, al menos desde el Gravetiense, de unas redes de contacto eficientes y amplias entre los grupos humanos, probablemente determinadas y favorecidas por las condiciones rigurosas y el paisaje abierto de las fases más frías del Pleniglaciar Superior (Zilhão 2007; Renard 2011). Tales condiciones implicaron también la necesidad de implementar mecanismos de refuerzo intergrupal para garantizar la supervivencia de dichos grupos.

Una de las hipótesis de trabajo que esperamos desarrollar en el futuro para confirmar el modelo propuesto se centrará en la investigación de los potenciales contactos entre la Extremadura portuguesa y la región central de la Meseta, pues tanto Peña Capón como los yacimientos lusos pertenecen a la cuenca hidrográfica del Tajo, la cual pudo haber servido como vía natural de comunicación. Para ello valoraremos además la presencia de sílex de ambas regiones en las industrias de finales del Gravetiense en el cercano valle del Côa (Aubry 2001; Aubry y Mangado 2006) que podría indicar contactos frecuentes entre los grupos humanos del centro y Oeste de la Península Ibérica en momentos inmediatamente anteriores a la aparición de las industrias protosolutrenses. El estudio en curso de las materias primas explotadas en Peña Capón aportará con seguridad datos interesantes en este sentido.

Las redes de contacto humano durante estos momentos del Pleniglaciar Superior pueden rastrearse asimismo en el registro gráfico. El núcleo artístico pleistocénico del Alto Jarama (Fig. 1B), en el que destaca la cueva de El Reno, situada a unos $11 \mathrm{~km}$. en línea recta de Peña Capón y para cuya primera fase de decoración algunos de nosotros ya propusimos una edad pleniglaciar (Alcolea et al. 1997a, 1997b, 2000), posee motivos arcaicos claramente paralelizables con el horizonte artístico más antiguo de la Meseta (Alcolea y Balbín 2003b). Dicho horizonte incorporaría tanto algunas fases de las cuevas castellanas más conocidas, como Los Casares, La Hoz o La Griega, como el grueso de la fase antigua de los conjuntos del Côa (Baptista 2008). Zilhão (2003, 2007), en su reciente análisis de estos últimos, señala sus fuertes analogías gráficas con algunos conjuntos cantábricos y del Suroeste francés. Todos estos datos, que proponen similitudes estilísticas entre grafías portuguesas, meseteñas, cantábricas y del mediodía francés, apuntan por tanto a la vigencia de una relativa homogeneidad gráfica durante el Pleniglaciar en el área de la inmediata expansión solutrense. Reivindican asimismo la idea de Villaverde (1994) sobre la generalización geográfica de los modelos artísticos premagdalenienses, y abundan en la posibilidad de que hubiera una tupida red de contactos en consonancia con los datos ofrecidos por las secuencias industriales de estas regiones.

\subsection{La ocupación de la Meseta durante el Pleniglaciar Superior}

Los datos aquí analizados proponen una ocupación humana relacionada con actividades cinegéticas en las estribaciones sur-orientales del Sistema Central durante el Pleniglaciar Superior (Estadio Isotópico Marino [MIS] 2), episodio que en la Europa mediterránea responde, en líneas generales, a un clima frío que condiciona un paisaje abierto dominado por una vegetación semi-desértica (Fletcher y Sánchez Goñi 2008: 456-457). La datación obtenida para el nivel 3 de Peña Capón (19.9 \pm 1 ka C14 BP ó 23.8 ka cal BP) se sitúa en un momento de gran inestabilidad climática y ambiental, dominado por la sucesión del Estadio (1) de Heinrich 2 (HS 2) y el Último Máximo Glaciar $(L G M)$, entre los que se desarrolla uno de los cortos períodos interestadiales (GI 2) detectados en los núcleos de hielo de Groenlandia (Sánchez Goñi y Harrison 2010). Consideramos excesivamente aventurado proponer una correlación 'de grano fino' entre la datación obtenida en el nivel 3 y los estadios climáticos señalados, básicamente por tres razones:

1) Los distintos proxies utilizados en la modelización del cambio climático pleistoceno proponen diferencias de cientos e incluso miles de años en la extensión y sucesión de los estadios y eventos del MIS 2 (Sánchez Goñi y Harrison 2010: tabs. 1 y 2). Ello dificulta su correlación con secuencias arqueológicas que exigen una resolución cronológica alta.

(1) Asumimos la diferenciación entre 'Estadio' y 'Evento' de Heinrich señalada por Sánchez Goñi y Harrison (2010: 2824).

Trab. Prehist., 70, N. ${ }^{\circ}$ 1, enero-junio 2013, pp 28-53, ISSN: 0082-5638 doi: $10.3989 /$ tp.2013.12101 
2) La aplicación generalizada en los depósitos arqueológicos de las largas secuencias paleoclimáticas obtenidas en las grandes masas de hielo y los registros polínicos de los sedimentos costeros resulta en ocasiones arriesgada, ya que algunos de los eventos reconocidos en las mismas no han podido ser identificados en las secuencias continentales, a menudo incompletas y de mucha menor resolución cronológica (González-Sampériz et al. 2010: 449). Además, la variedad biogeográfica de los diferentes territorios impone peculiaridades no detectadas a escalas más amplias (Burroughs 2005: 88). Ambas circunstancias adquieren una gran relevancia en la Meseta, donde aún contamos con escasos datos paleoclimáticos y paleoambientales correspondientes al MIS 2 (Ruiz Zapata et al. 2000; Valdeolmillos et al. 2003; Vegas et al. 2008; Tapias et al. 2012), que nos permitan valorar la adecuación de su secuencia a la detectada en los proxies de escala global.

3) Los datos cronométricos obtenidos en Peña Capón son aún demasiado escasos y problemáticos como para asegurar una fiabilidad estadística aceptable que permita establecer una correlación con el registro paleoclimático. Tampoco contamos con datos paleoecológicos procedentes de su estratigrafía, y los obtenidos a partir de coprolitos de hiena en el cercano yacimiento de Los Torrejones (Tamajón) (Carrión et al. 2007), o aquellos recuperados en los depósitos fluviales del Tajo a su paso por Toledo (Ruiz Zapata et al. 2004), no incluyen cronologías correspondientes al MIS 2.

En todo caso, no resulta aventurado deducir que la ocupación del nivel 3, indudablemente desarrollada durante el Pleniglaciar Superior, debió producirse en un momento de condiciones climáticas y ambientales rigurosas, si no muy rigurosas. De ser así, incluso si valoramos la posibilidad de un hipotético rejuvenecimiento de la muestra datada, sería lógico tomar como referencia teórica para la edad real del nivel la cronología asignada al núcleo protosolutrense de la Extremadura portuguesa (c. $21.5-21.0 \mathrm{ka} \mathrm{C14} \mathrm{BP} \mathrm{ó} \mathrm{c.} 25.5-25.0$ $\mathrm{ka}$ cal $\mathrm{BP}$ ), el contexto paleoclimático seguiría siendo similar, incluso con una mayor probabilidad de enmarcarse en pleno HS 2 (Sánchez Goñi y Harrison 2010: tabla 2).

Estos datos son una relevante contribución a la cada vez más antigua discusión sobre el poblamiento superopaleolítico del interior peninsular (Delibes y Díez 2006). La discusión hunde sus raíces en el estereotipo tradicional que presumía un vacío poblacional en la Meseta durante las oscilaciones más frías de la última glaciación como consecuencia del rigor climático propio de las zonas altas (Breuil y Obermaier 1913: 15). Las últimas interpretaciones que han postulado la despoblación mesetaria durante el último Pleniglaciar llegan a conceder la posibilidad de ocupaciones esporádicas en algunas zonas coincidiendo con los momentos de mayor bonanza climática, y siempre como resultado de desplazamientos de carácter estacional desde las áreas clásicas de desarrollo del Paleolítico Superior peninsular (Ripoll et al. 1997: 83; Corchón 1997: 166, 2002: 130; Straus et al. 2000: 561). Sin embargo, numerosos datos nos obligan a reconsiderar esta idea. Desde hace tiempo se conocen evidencias sólidas sobre la ocupación pleniglaciar de otros territorios con condiciones climáticas similares a la Meseta, como el Prepirineo aragonés (Utrilla et al. 2010: 29), o aún más extremas, como las llanuras de la Europa central y oriental o la región siberiana (Hoffecker 2002: 196; Verpoorte 2009: 79). Además en el interior peninsular se han venido revelando en los últimos años numerosos datos que indican que la ocupación de amplias zonas meseteñas no sería tan esporádica.

A la ya comentada atribución pleniglaciar según criterios estilísticos de una parte de las grafías paleolíticas conocidas en el interior peninsular, se une el hecho de que el grueso de la fauna representada en el arte paleolítico del interior, aunque encuadrable en el estereotipo euritermo, lejos de responder a nichos ecológicos templados, posee un marcado sesgo templado-frío, cuando no revela directamente la existencia de nichos ecológicos francamente fríos (Alcolea y Balbín 2003a: 488). Por otro lado, a las referencias clásicas sobre industrias solutrenses en los areneros de la ciudad de Madrid, confirmadas por estudios recientes (Martínez de Merlo 1984; Baena y Carrión 2002, 2006), se han sumado nuevos datos sobre la ocupación solutrense del valle del Manzanares madrileño (Tapias et al. 2012). Entre estos últimos resulta especialmente relevante la atribución al Solutrense del yacimiento clásico de Las Delicias (Obermaier y Wernert 1918; Santonja et al. 2000), cuestión ya apuntada por algunos investigadores (Baena y Carrión 2002), y que ha sido confirmada gracias a la excavación de parte de los depósitos aún conservados en el sitio (Alcaraz-Castaño et al. 2012). Más al Oeste, las dataciones obtenidas recientemente para la Sala de las 
Chimeneas de la cueva de Maltravieso (Cáceres), que sitúan el nivel A en cronologías avanzadas del MIS 2 (Canals et al. 2010), son otro argumento a favor de la ocupación superopaleolítica del interior peninsular en momentos anteriores al Tardiglaciar. De la misma forma, la comentada presencia de sílex del Sistema Central en los niveles gravetienses del valle del Côa puede interpretarse como un indicio de la presencia humana en el centro de la Meseta durante estos momentos.

La estratigrafía de Peña Capón, de la que se desprenden varios episodios de ocupación humana en el abrigo durante al menos tres momentos del Pleniglaciar Superior, supone, probablemente, el argumento de mayor peso a favor de una ocupación más que esporádica de la Meseta durante momentos de un fuerte rigor climático. Ello refleja la adaptabilidad ecológica de los grupos humanos del Paleolítico Superior. Que Peña Capón pueda haberse enmarcado en un territorio que actuara como refugio ecológico durante los momentos más fríos del Pleniglaciar, al situarse al amparo de las estribaciones del Sistema Central (Tzedakis et al. 2002), es algo que, aunque sugerido para regiones cercanas en diversos momentos del Pleistoceno Medio y Superior (Carrión et al. 2007), por ahora no estamos en condiciones de valorar, y desde luego choca frontalmente con las condiciones rigurosas que soporta actualmente la zona. Más allá del estudio faunístico, poco informativo en este sentido, no disponemos de otras analíticas paleoambientales para pronunciarnos sobre esta problemática, lo cual esperamos paliar de posibilitarse un futuro acceso al yacimiento.

Si se aceptan los datos aquí presentados, la discusión clásica sobre la habitabilidad del interior peninsular durante el Pleniglaciar Superior debería abandonarse, o al menos replantearse en términos que desecharan finalmente el tópico de una Meseta desolada durante buena parte del Paleolítico Superior. Si la insistencia en la interpretación clásica durante tanto tiempo se ha debido fundamentalmente a la falta de estudios científicos en la región, su superación definitiva pasa por un mayor esfuerzo investigador en los años venideros.

\section{AGRADECIMIENTOS}

Álvaro Arrizabalaga, José Manuel Maíllo, Felipe Cuartero y Paloma de la Peña nos han brindado interesantes comentarios sobre la industria lítica del nivel 3 de Peña Capón. José María Barco, Sandra Benítez, Nuria Fernández, Alba Santamaría e Irene Rivera han colaborado en los trabajos de laboratorio. Elizabeth Díaz ha participado en la fotografía de buena parte de la industria lítica y ósea. João Zilhão nos facilitó un trabajo suyo aún sin publicar. Primitiva Bueno y Felipe Cuartero leyeron una primera versión de este trabajo $\mathrm{y}$ aportaron valiosas sugerencias sobre su forma y contenido. En todo caso, las interpretaciones vertidas en el texto son responsabilidad exclusiva de los autores.

Parte de esta investigación ha sido realizada gracias a una ayuda FPU concedida por el Ministerio de Educación y Ciencia (referencia AP20061121) al primer firmante del artículo.

\section{BIBLIOGRAFÍA}

Alcaraz-Castaño, M. 2007: "El Ateriense del Norte de África y el Solutrense peninsular. ¿Contactos transgibraltareños en el Pleistoceno Superior?". Munibe (Antropologia - Arkeologia) 58: 101-126.

Alcaraz-Castaño, M.; López Recio, M.; Roca, M.; Tapias, F.; Rus, I.; Baena, J.; Morín, J.; Pérez-González, A. y Santonja, M. 2012: "Nuevos datos sobre el yacimiento solutrense de Las Delicias (Madrid, España)". Resúmenes Congreso Internacional El Solutrense: centenario de las excavaciones en La Cueva de Ambrosio (Vélez Blanco, Almería, España 2012): 113-114.

Alcolea, J. J. y Balbín, R. de 2003a: "Témoins du froid. La faune dans l'art rupestre paléolithique de l'intérieur péninsulaire". L'Anthropologie 107 (4): 471-500.

Alcolea, J. J. y Balbín, R. de 2003b: "El Arte Rupestre Paleolítico del interior peninsular. Elementos para el estudio de su variabilidad regional". En R. de Balbín y P. Bueno (eds.): El Arte Prehistórico desde los inicios del siglo XXI. Primer Symposium Internacional de Arte Prehistórico de Ribadesella (Ribadesella 2001): 223-253. Ribadesella.

Alcolea, J. J.; Balbín, R. de; García, M. A. y Jiménez, P. J. 1997a: "Nouvelles decouvertes d'Art Pariétal Paléolithique á la Meseta: La grotte del Reno (Valdesotos, Guadalajara)". L'Anthropologie 101: 144-163.

Alcolea, J. J.; Balbín, R. de; García, M. A. y Jiménez, P. J. 1997b: "Nuevos descubrimientos de arte rupestre paleolítico en el centro de la Península Ibérica: La cueva del Reno (Valdesotos, Guadalajara)". En R. de Balbín y P. Bueno (eds.): II Congreso de Arqueo- 
logía Peninsular (Zamora 1996) I, Paleolítico y Epipaleolítico: 239-257. Zamora.

Alcolea, J. J.; Balbín, R. de; García Valero, M. A.; Jiménez, P. J.; Aldecoa, A.; Casado, A. B.; Andrés, B. de; Ruiz Pedraza, S.; Sainz Rubio, P. y Suárez Rueda, N. 1997c: "Avance al estudio del poblamiento paleolítico del Alto Valle del Sorbe (Muriel, Guadalajara)". En R. de Balbín y P. Bueno (eds.): II Congreso de Arqueología Peninsular (Zamora 1996) I, Paleolítico y Epipaleolítico: 201-218. Zamora.

Alcolea, J. J.; Balbín, R. de; Jiménez, P.; García, M. A. y Foyo, A. 2000: "La cueva de El Reno (Valdesotos, Guadalajara): una visión de conjunto de su arte parietal paleolítico". $3{ }^{\circ}$ Congresso de Arqueología Peninsular (Vila Real 1999) 2: 525-540. Porto.

Alcolea, J. J.; García Valero, M. A. y Alcaína, A. 1995: "El poblamiento prehistórico antiguo en el sector suroriental del Sistema Central. Investigaciones en el valle alto del Sorbe, Guadalajara". Raña 19: 37-40.

Almeida, F. 2000: The Terminal Gravettian of Portuguese Estremadura: Technological Variability of the Lithic Industries. PhD Dissertation. Southern Methodist University. Dallas. Texas, EUA. http://www. academia.edu/229888/The_Terminal_Gravettian_of_ Portuguese_Estremadura._Technological_variability_ of_the_lithic_industries (consulta 13-II-2012).

Almeida, F.; Matias, H.; Carvalho, R.; Pereira, T.; Pinto, A. y Holliday, T. 2010: "New Data on the Transition from the Gravettian to the Solutrean in Portuguese Estremadura". Paleoanthropology Society Meeting Abstracts (St. Louis, MO 2010). Paleoanthropology 2010: A1.

Almeida, F.; Moreno-García, M. y Angelucci D. 2009: "From under the bulldozer's claws: the EE15 Late Gravettian occupation surface of the Lagar Velho rock-shelter". World Archaeology 41 (2): 242-261.

Altuna, J. 1986: "The mammalian faunas from the prehistoric site of La Riera". En L. G. Straus y G. Clark (eds.): La Riera Cave. Stone Age HunterGatherer Adaptations in Northern Spain. Anthropological Research Paper 36, Arizona State University. Arizona: 237-274.

Aubry, T. 2001: "L'occupation de la basse vallée du Côa pendant le Paléolithique supérieur". En J. Zilhão, T. Aubry y A. F. Carvalho (eds.): Les premiers hommes modernes de la Péninsule Ibérique, Actes $d u$ Colloque de la commission VIII de l'UISSP. Trabalhos de Arqueologia 17, Instituto Portugûes de Arqueologia. Lisboa: 253-273.

Aubry, T.; Detrain, L. y Kervazo B. 1995: "Les niveaux intermédiaires entre le Gravettien et le Solutréen de l'Abri Casserole (Les Eyzies de Tayac): Mise en évidence d'un mode de production original de microlithes et implications". Bulletin de la Société Préhistorique Française 92 (3): 296-301.

Aubry, T. y Mangado, J. 2006: "The Cõa Valley (Portugal): Lithic Raw Material and the Reconstruction of Upper Palaeolithic Settlement Patterns". En C.
Bressy, A. Burke, P. Chalard y H. Martin (ed.): Notions de territoire et de mobilité: Exemples d'Europe et des premières nations en Amérique du Nord avant le contact européen. Études et recherches archéologiques de Université de Liège 116. Lieja: 41-49.

Aubry, T.; Zilhão, J.; Almeida, F. y Fontugne, M. 1997: "Production d'armatures microlithiques pendant le Paléolithique supérieur et le Mésolithique au Portugal“. En R. de Balbín y P. Bueno (eds.): II Congreso de Arqueología Peninsular (Zamora 1996) I, Paleolítico y Epipaleolítico: 259-272. Zamora.

Aura, J. E.; Jordá, J. F. y Fortea, F. J. 2006: “La cueva de Nerja (Málaga, España) y los inicios del Solutrense en Andalucía". Zephyrus 59: 67-88.

Aura, J. E.; Jordá, J. F.; Pérez, M.; Badal, E.; Morales, J. V.; Avezuela, B.; Tiffagom, M. y Jardón, P. 2010: "Treinta años de investigación sobre el Paleolítico superior de Andalucía: la Cueva de Nerja (Málaga, España)". En X. Mangado (ed.): El Paleolítico superior peninsular. Novedades del siglo XXI. Homenaje al profesor Javier Fortea. Monografies del Seminari d'Estudis i Recerques Prehistòriques 88, Universitat de Barcelona, Barcelona: 149-172.

Baena, J. y Carrión, E. 2002: "Los materiales solutrenses". En C. Blasco Bosqued (coord.): La Colección Bento del Museu d'Arqueologia de Catalunya. Una nueva mirada a la prehistoria de Madrid. Museu d'Arqueologia de Catalunya. Barcelona: 79-130.

Baena, J. y Carrión, E. 2006: "Contexto geográfico: un marco para el desarrollo del Paleolítico Superior de Madrid". En M. R. Lucas Pellicer, L. M. Cardito Rollán y J. Gómez Hernanz (eds.): Dibujos en la roca: el arte rupestre en la Comunidad de Madrid. Arqueología, Paleontología y Etnografía 11, Consejería de Cultura y Deportes, Comunidad de Madrid 11. Madrid: 43-55.

Baptista, A. M. 2008: O paradigma perdido. O Vale do Côa e a Arte Paleolitica de ar libre em Portugal. Edições Afrontamento e Parque Arqueologico do Vale do Côa. Vila Nova de Foz Côa.

Bicho, N. F.; Gibaja, J. F.; Stiner, M. y Manne, T. 2010: "Le paléolithique supérieur au sud du Portugal: le site de Vale Boi". L'Anthropologie 114 (1): 48-67.

Bosselin, B. y Djindjian, F. 1997: "Une révision du Solutréen de Laugerie-Haute et le problème des transitions Gravettien-Solutréen et Solutréen-Badegoulien en Aquitaine". Bulletin de la Société Préhistorique Française 94: 443-454.

Breuil, H. y Obermaier H. 1913: "Institut de Paléontologie Humaine. Travaux exécutés en 1912”. L'Anthropologie XXIV: 1-16.

Bronk Ramsey, C. 2009: "Bayesian analysis of radiocarbon dates". Radiocarbon 51 (1): 337-360.

Burroughs, W. J. 2005: Climate Change in Prehistory. The End of the Reign of Chaos. Cambridge University Press. Cambridge.

Cacho, C.; Martos, J. A.; Jordá, J.; Yravedra, J.; Avezuela, B.; Valdivia, J. y Martín, I. 2010: "El Paleo-

Trab. Prehist., 70, N. ${ }^{\circ}$ 1, enero-junio 2013, pp 28-53, ISSN: 0082-5638

doi: $10.3989 /$ tp.2013.12101 
lítico superior en el interior de la Península Ibérica. Revisión crítica y perspectivas de futuro". En X. Mangado (ed.): El Paleolítico superior peninsular. Novedades del siglo XXI. Homenaje al profesor Javier Fortea. Monografíes del Seminari d'Estudis i Recerques Prehistòriques 8, Universitat de Barcelona. Barcelona: 115-136.

Canals, A.; Rodríguez-Hidalgo, A.; Peña, L.; Mancha, E.; García-Díez, M.; Bañuls, S.; Euba, I.; LópezGarcía, J. M.; Barrero, N.; Bermejo, L.; García, F. J.; Mejías, D.; Modesto, M.; Morcillo, A.; Aranda, V. y Carbonell, E. 2010: "Nuevas aportaciones al Paleolítico superior del suroeste peninsular: la cueva de Maltravieso, más allá del santuario extremeño de las manos". En X. Mangado (ed.): El Paleolítico superior peninsular. Novedades del siglo XXI. Homenaje al profesor Javier Fortea. Monografies del Seminari d'Estudis i Recerques Prehistòriques 88, Universitat de Barcelona, Barcelona: 199-218.

Carrión, J. S.; Scott, L.; Arribas, A.; Fuentes, N.; GilRomera, G. y Montoya, E. 2007: "Pleistocene landscapes in central Iberia inferred from pollen analysis of hyena coprolites". Journal of Quaternary Science 22 (2): 191-202.

Cascalheira, J.; Marreiros, J. y Évora M. 2010: "From Gravettian to Solutrean in Southwestern Iberia: a technological perspective". Poster at Paleoanthropology society 2010 annual meeting, St. Louis, Missouri, USA.

Corchón, M. S. 1997: La cueva de La Griega de Pedraza (Segovia). Arqueología en Castilla y León Memorias 3, Junta de Castilla y León. Zamora.

Corchón, M. S. 2002: “El Tardiglaciar y la transición al Postglaciar en la Meseta norte española: una revisión de síntesis". Zephyrus 55: 85-142.

Davidson, I. 1989: La economía del final del Paleolítico en la España oriental. Trabajos Varios del Servicio de Investigación Prehistórica 85, Diputación Provincial. Valencia.

Delibes de Castro, G. y Díez Martín, F. 2006: “¿Una Meseta desolada? Estado actual de la investigación sobre el Paleolítico Superior en las regiones interiores de la Península Ibérica”. En G. Delibes de Castro y F. Díez Martín (eds.): El Paleolítico Superior en la Meseta Norte española. Studia Archaeologica 94, Universidad de Valladolid, Fundación Duques de Soria. Valladolid: 11-40.

Domínguez-Rodrigo, M. 1997: "Meat eating by early hominids at FLK Zinj 22 Site, Olduvai Gorge, Tanzania: An experimental approach using cut-mark data". Journal of Human Evolution 33: 669-690.

Domínguez-Rodrigo, M. y Barba, R. 2005: “A study of cut marks on small-sized carcasses and its application to the study of cut marked bones from small mammals at the FLK Zinj site". Journal of Taphonomy 3 (3): 121-134.

Fletcher, W. J. y Sánchez Goñi, M. F. 2008: “Orbitaland sub-orbital climate impacts on vegetation of the western Mediterranean basin over the last 48,000 yr". Quaternary Science Reviews 70: 451-464.

Fullola, J. M.; Bartrolí, R.; Cebrià, A.; Begadá, M. M.; Farell, D. y Nadal, J. 1994: "El Paleolítico Superior de Catalunya: El Gravetiense de la Balma de la Griera (Calafell, Baix Penedès)". En Actas del I. ${ }^{\text {er }}$ Congreso de Arqueología Peninsular (Porto 1993), Trabalhos de Antropologia e Etnologia III: 35-41.

García Díez, M. y Cebrià, A. 2003: "Evidencia gráfica mueble del Paleolítico Superior antiguo: La Balma de la Griera (Calafell, Baix Penedès, Tarragona)". Zephyrus 56: 39-48.

González-Sampériz, P.; Leroy, S. A. G.; Carrión, J. S.; Fernández, S.; García-Antón, M.; Gil-García, M. J.; Uzquiano, P.; Valero-Garcés, B. y Figueiral, I. 2010: "Steppes, savannahs, forests and phytodiversity reservoirs during the Pleistocene in the Iberian Peninsula". Review of Palaeobotany and Palynology 162 (3): 427-457.

Higham, T. F. G. 2011: "European Middle and Upper Palaeolithic radiocarbon dates are often older than they look: problems with previous dates and some remedies". Antiquity 85 (327): 235-249.

Hoffecker, J. 2002: Desolate landscapes. Ice-age settlement in Eastern Europe. Rutgers University Press. Nuevo Brunswick, Nueva Jersey, London.

Iturbe, G.; Fumanal, M.; Carrión, J.; Cortell, E.; Martínez, R.; Guillem, P.; Garralda, M. y Vandermeersch, B. 1993: "Cova Beneito (Muro, Alicante): una perspectiva interdisciplinar". Recerques del Museo d'Alcoi 2: 23-88.

Martínez de Merlo, A. 1984: "El Paleolítico Superior en el valle del Manzanares. El yacimiento de El Sotillo". Boletín del Museo Arqueológico Nacional 11: 47-68.

Moreno-García, M. y Pimenta, C. 2002: "The paleofaunal context". En J. Zilhão y E. Trinkaus (eds.): Portrait of the Artist as a Child. The Gravettian Human Skeleton from the Abrigo do Lagar Velho and its Archeological Context. Trabalhos de Arqueologia 22, Instituto Português de Arqueología. Lisboa: 112-131.

Mosquera, M.; Ollé, A.; Pérez-González, A.; Rodríguez, X. P.; Vaquero, M.; Vergés, J. M. y Carbonell, E. 2007: "Valle de las Orquídeas: un yacimiento al aire libre del Pleistoceno Superior en la Sierra de Atapuerca (Burgos)"'. Trabajos de Prehistoria 64 (2): 143-155.

Mozota, M. 2009: "El utillaje óseo musteriense del nivel 'D' de Axlor (Dima, Vizcaya): análisis de la cadena operativa". Trabajos de Prehistoria 66 (1): 27-46.

Obermaier, H. y Wernert, P. 1918: Yacimiento Paleolítico de las Delicias. Memorias de la Real Sociedad Española de Historia Natural XI, 1. Madrid: 5-35.

Parcerisas, J. y Tarriño, A. 2008: "Los sílex de los páramos del Tajo (Sector Norte): Avance de una definición formal de aplicación arqueológica". En E. García-Soto, M. A. García Valero y J. P. Martínez 
(eds.): Actas del Segundo Simposio de Arqueología de Guadalajara (Molina de Aragón 2006): 73-87. Guadalajara.

Patou-Mathis, M. 2002: Fiches typologiques de l'industrie osseuse préhistorique. Cahier X: Retouchoirs, compresseurs, percuteurs. Os à impressions et à éraillures. Société Préhistorique Française. Paris.

Pelegrin, J. 1995: Technologie Lithique: Le Châtelperronien de Roc-de-Combe (Lot) et de La Côte (Dordogne). Cahiers du Quaternaire 20, Centre National de la Recherche Scientifique. Paris.

Pelegrin, J. 2000: "Les techniques de débitage laminaire au Tardiglaciare: critères de diagnose et quelques réflexions". En B. Valentin y M. Christensen (eds.): L'Europe centrale et septentrionale au Tardiglaciare. Actes de la Table-Ronde Nemours 1997. Mémoires du Musée du Ile de France 7. Nemours: 73-86.

Peña Alonso, P. de la 2009: "Revisión crítica de los conjuntos líticos gravetienses y su contexto arqueológico en la Península Ibérica". Complutum 20 (1): 29-53.

Peña Alonso, P. de la 2011: "Sobre la identificación macroscópica de las piezas astilladas: propuesta experimental". Trabajos de Prehistoria 68 (1): 79-98.

Quero, S. 2002: "La investigación del Paleolítico en Madrid durante el franquismo (1936-1971)". En J. Panera y S. Rubio (eds.): Bifaces y Elefantes. La investigación del Paleolítico Inferior en Madrid. Zona Arqueológica 1, Museo Arqueológico Regional, Alcalá de Henares: 168-193.

Rasilla, M. de la 1994: "Introducción: El Solutrense en el contexto del Paleolítico Superior Occidental". Monográfico. El Solutrense en la Península Ibérica. Férvedes 1: 9-19.

Rasilla, M. de la 1999: "Los principios del Solutrense". En XXIV Congreso Nacional de Arqueología (Cartagena 1997), 1 Los problemas del Paleolítico Superior en el ámbito mediterráneo peninsular: 8185. Murcia.

Reimer, P. J.; Baillie, M.; Bard, E.; Bayliss, A.; Beck, J.; Blackwell, P.; Bronk Ramsey, C.; Buck, C.; Burr, G.; Edwards, R.; Friedrich, M.; Grootes, P.; Guilderson, T.; Hajdas, I.; Heaton, T.; Hogg, A.; Hughen, K.; Kaiser, K.; Kromer, B.; McCrmac, F.; Manning, S.; Reimer, R.; Richards, D.; Southon, J.; Talamo, S.; Turney, C.; van der Plicht, J. y Weyhenmeyer, C. 2009: "IntCal09 and Marine09 Radiocarbon Age Calibration Curves, 0-50,000 Years cal BP". Radiocarbon 51 (4), IntCal09 special volume: 1111-1150.

Renard, C. 2010: Les premières expressions du Solutréen dans le Sud-ouest français. Evolution technoéconomique des équipements lithiques au cours $d u$ Dernier Maximum Glaciaire. British Archaeological Reports International Series 2070, John and Erica Hedges Ltd. Oxford.

Renard, C. 2011: "Continuity or discontinuity in the Late Glacial Maximum of south-western Europe: the formation of the Solutrean in France". World Archaeology 43 (4): 726-743.
Ripoll, S.; Cacho, C. y Municio, L. 1997: "El Paleolítico Superior en la Meseta". Espacio, Tiempo y Forma, Serie I, Prehistoria y Arqueología 10: 55-87.

Ruiz Zapata, M. B.; Dorado, M.; Valdeolmillos, A.; Gil García, M. J.; Martín Arroyo, T. y Pérez-González, A. 2004: "Registro paleoambiental y paleoclimático del Pleistoceno Medio y Superior en depósitos fluviales del valle del río Tajo (Toledo)". Miscelánea en Homenaje a Emiliano Aguirre II. Paleontología. Zona Arqueológica 4, Museo Arqueológico Regional. Alcalá de Henares: 507-517.

Ruiz Zapata, M. B.; Pérez-González, A.; Dorado, M.; Valdeolmillos, A.; Bustamante, I. y Gil-García, M. J. 2000: "Caracterización climática de las etapas áridas del Pleistoceno Superior en la Región Central Peninsular". Geotemas 1 (4): 273-278.

Sánchez Goñi, M. F. y Harrison, S. P. 2010: "Millennial-scale climate variability and vegetation changes during the Last Glacial: Concepts and terminology". Quaternary Science Reviews 29 (21-22): 2823-2827.

Santonja, M.; Pérez-González, A. y Vega, L. G. 2000: "El yacimiento de la estación de las Delicias (Madrid). La investigación del Paleolítico en el Manzanares". Homenaje al profesor Vallespí. SPAL 9: 525-555.

Soler, N. y Maroto, J. 1998: "Les grottes du Reclau (Serinyà, Catalogne) et le Gravettien du Méditerranéen ibérique". XIII International Congress UISPP (Forli 1996), 6. The Upper Palaeolithic: 295-312. Forlì.

Sonneville-Bordes, D. de y Perrot, J. 1954; 1955; 1956a; 1956b: "Lexique typologique du Paléolithique supérieur". Bulletin de la Société Préhistorique Française 51: 327-335; 52: 76-79; 53: 408412; 53: 547-559.

Soriano, S.; Villa, P.; Wadley, L. 2007: "Blade technology and tool forms in the Middle Stone Age of South Africa: the Howiesons Poort and postHowiesons Poort at Rose Cottage Cave". Journal of Archaeological Science 34 (5): 681-703.

Straus, L. G. 1992: Iberia before the Iberians. The Stone Age Prehistory of Cantabrian Spain. University of New Mexico Press. Albuquerque.

Straus, L. G. 1995: "Reflexiones sobre el estado de la investigación del Solutrense vasco-cantábrico". Férvedes 2: 23-33.

Straus, L. G.; Bicho, N. y Winegardner, A. C. 2000: "The Upper Palaeolithic settlement of Iberia: firstgeneration maps". Antiquity 74: 553-566.

Tapias, F.; López-Recio, M.; Manzano, I.; Alcaraz-Castaño, M.; Morín, J.; Sesé, C.; Dapena, L.; Alarcón, A.; Yravedra, J. y Arteaga, C. 2012: "Geoarqueología y paleontología de los depósitos de Pleistoceno Superior del antiguo arroyo Abroñigal (Cuenca del Manzanares, Madrid): el yacimiento del Puente de los Tres Ojos". Cuaternario y Geomorfología 26, 1-2: 105-132.

Terradas, X. 2003: "Discoid Flaking Method: Conception and Technological Variability". En M. Peresani

Trab. Prehist., 70, N. ${ }^{\circ}$ 1, enero-junio 2013, pp 28-53, ISSN: 0082-5638

doi: $10.3989 /$ tp.2013.12101 
(ed.): Discoid Lithic Technology: Advances and Implications. British Archaeological Reports, International Series 1120, Archaeopress. Oxford: 19-31.

Tiffagom, M. 2006: De la Pierre à l'Homme. Essai sur une paléoanthropologie solutréenne. Études et recherches archéologiques de Université de Liège 113. Lieja.

Tiffagom, M.; Aura, J. E.; Villaverde, V. y Fullola, J. M. 2007: "Entre Gravettien et Solutréen en Espagne méditerranéenne: mise en évidence d'une phase intermédiaire à composante mixte?". En M. Almeida, B. Walter y M. J. Neves (eds.): Le Solutréen, 40 ans après Smith 1966. Pré-actes du colloque international de Preuilly-sur-Claise, 2831 octobre 2007.

Tzedakis, P. C.; Lawson, I. T.; Frogley, M. R.; Hewitt, G. M. y Preece, R. C. 2002: "Buffered Tree Population Changes in a Quaternary Refugium: Evolutionary Implications". Science 297 (5589): 2044-2047.

Utrilla, P.; Montes, L.; Mazo, C.; Alday, A.; Rodanés, J. M.; Blasco, M. F.; Domingo, R. y Bea, M. 2010: "El Paleolítico superior en la cuenca del Ebro a principios del siglo XXI. Revisión y novedades". En X. Mangado (ed.): El Paleolítico superior peninsular. Novedades del siglo XXI. Homenaje al profesor Javier Fortea. Monografies del Seminari d'Estudis i Recerques Prehistòriques 88, Universitat de Barcelona. Barcelona: 23-61.

Valdeolmillos, A.; Dorado, M.; Ruiz Zapata, M. B.; Bardají, T. y Bustamante, I. 2003: "Paleoclimatic record of the Last Glacial Cycle at Las Tablas de Daimiel National Park (Southern Iberian Meseta, Spain)". En M. B. Ruiz Zapata, M. Dorado, A. Valdeolmillos, M. J. Gil-García, T. Bardají, I. Bustamante e I. Martínez Mendizábal (eds.): Quaternary Climatic Changes and Environmental Crises in the Mediterranean Region. Universidad de Alcalá. Alcalá de Henares: 222-228.

Vegas, J.; Ruiz Zapata, M. B.; Ortiz, J. E.; Galán, J.; Torres, T.; García-Cortés, A.; Pérez-González, A. y Gallardo-Millán, J. L. 2008: "Identificación de las principales fases áridas del Pleistoceno superior en el registro sedimentario lacustre del mar de Fuentillejo (Campo de Calatrava)". Geotemas 10: 1467-1470.

Verpoorte, A. 2009: "Limiting factors on early modern human dispersals: The human biogeography of late Pleniglacial Europe". Quaternary International 201 (1-2): 77-85.

Villaverde, V. 1994: Arte Paleolítico de la Cova del Parpalló. Estudio de la colección de plaquetas y cantos grabados y pintados. Servei d'Investigació Prehistòrica, Diputación de Valencia. Valencia.
Villaverde, V.; Martínez-Valle, R.; Román, D.; Iborra, M. P. y Pérez Ripoll, M. 2007-2008: "El Gravetiense de la vertiente mediterránea ibérica: reflexiones a partir de la secuencia de la Cova de Les Cendres (Moraira, Alicante). Homenaje a Ignacio Barandiarán Maestu" I. Veleia 24-25: 445-468.

Villaverde, V. y Román, D. 2004: "Avance al estudio de los niveles gravetienses de la Cova de Les Cendres. Resultados de la excavación del sondeo (Cuadros A/B/C-17) y su valoración en el contexto del Gravetienses mediterráneo ibérico". Archivo de Prehistoria Levantina XXV: 19-59.

Yravedra, J. 2001: "Subsistencia en el Paleolítico Superior Inicial de la Cornisa Cantábrica". Gallaecia 21: 45-60.

Yravedra, J. 2007: “Aproximaciones tafonómicas a los cazadores de la segunda mitad del Pleistoceno Superior de la mitad norte del interior de la Península Ibérica". Arqueoweb 9 (1) http://www.ucm.es/info/ arqueoweb/pdf/9-2/josete.pdf (consulta 21-X-2012).

Yravedra, J y Gómez Castanedo, A. 2010: "Las estrategias de subsistencia en la región central de la cornisa cantábrica. ¿Continuidad o ruptura?”. Nivel Cero 12: 35-51.

Zilhão, J. 1997: O Paleolítico Superior da Estremadura portuguesa. Edições Colibri. Lisboa.

Zilhão, J. 2003: "Vers une chronologie plus fine du cycle ancien de l'art paléolithique de la Côa: quelques hypothèses de travail". En R. de Balbín y P. Bueno (eds.): El Arte Prehistórico desde los inicios del siglo XXI. Primer Symposium Internacional de Arte Prehistórico de Ribadesella (Ribadesella 2001): 75-90. Ribadesella.

Zilhão, J. 2007: "Forty years after Roche 1964: a farwest view of the Solutrean". En M. Almeida, B. Walter y M. J. Neves (eds.): Le Solutréen, 40 ans après Smith '1966. Pré-actes du colloque international de Preuilly-sur-Claise, 28-31 octobre 2007.

Zilhão, J. y Aubry, T. 1995: "La pointe de Vale Comprido et les origines du Solutréen". L'Anthropologie 99 (1): 125-142.

Zilhão, J.; Aubry, T. y Almeida, F. 1997: "L'Utilisation du Quartz pendant la transition Gravettien-Solutréen au Portugal. Préhistoire Anthropologie Méditerranéennes 6: 289-303.

Zilhão, J.; Aubry, T. y Almeida, F. 1999: "Un modèle technologique pour le passage du Gravettien au Solutréen dans le sud-ouest de l'Europe". En D. Sacchi (ed.): Les faciès leptolithiques du nord-ouest méditerranéen: milieux naturels et culturels. Actes du XXIVe Congrès Préhistorique de France (Carcassonne 1994): 165-183. Paris. 